\title{
A new archaic homodont toothed cetacean (Mammalia, Cetacea, Odontoceti) from the early Miocene of Peru
}

\author{
Olivier LAMBERT \\ Institut royal des Sciences naturelles de Belgique, D.O. Terre et Histoire de la Vie, \\ 29 rue Vautier, B-1000 Brussels (Belgium) \\ olivier.lambert@naturalsciences.be \\ Christian DE MUIZON
}

Département Histoire de la Terre, Muséum national d'Histoire naturelle, Centre de Recherche sur la Paléobiodiversité et les Paléoenvironnements (CR2P: CNRS, MNHN, UPMC-Paris 06; Sorbonne Universités), case postale 38, 57 rue Cuvier, F-75231 Paris cedex 05 (France) muizon@mnhn.fr

Giovanni BIANUCCI

Università di Pisa, Dipartimento di Scienze della Terra, via S. Maria 53, I-56126 Pisa (Italy)

bianucci@dst.unipi.it

Published on 27 March 2015

urn:Isid:zoobank.org:pub:B3DF8C10-7139-4CBA-9093-0795B6ACBBC7

Lambert O., De Muizon C. \& Bianucci G. 2015. - A new archaic homodont toothed cetacean (Mammalia, Cetacea Odontoceti) from the Early Miocene of Peru. Geodiversitas 37 (1): 79-108. http://dx.doi.org/10.5252/g2015n1a4

\section{ABSTRACT}

Apart from a few exceptions, extant odontocetes (toothed cetaceans) exhibit a roughly homodont dentition. The transition from basilosaurid-like double-rooted cheek teeth with accessory denticles to single-rooted conical teeth occurred during the late Oligocene-early Miocene. At that time, several clades of now extinct, homodont and predominantly long-snouted odontocetes appeared in the fossil record. Among them, members of the genera Argyrocetus Lydekker, 1893 and Macrodelphinus Wilson, 1935, from the early Miocene of the Northeast Pacific and Argentina, were tentatively attributed to the family Eurhinodelphinidae. However, due to the fragmentary state of the specimens, unambiguous apomorphies of the family could not be detected. Based on two well-preserved skulls with associated mandibular elements, discovered in early Miocene layers of the Chilcatay Formation (Pisco Basin, Peru), we report on a new genus and species of long-snouted homodont odontocete, Chilcacetus cavirhinus n. gen., n. sp. Characterized by, among others, the presence of alveoli on the anterior premaxillary portion of the rostrum, the lack of a lateral groove on the rostrum, anterodorsally elevated nasals, a possibly autapomorphic cavity between nasals and mesethmoid in the posterior wall of the bony nares, a high temporal fossa, and the absence of ankylosis along the mandibular symphysis, C. cavirhinus n. gen., n. sp. does not fit in any of the known odontocete families, but shares several morphological features with Argyrocetus spp.

KEY WORDS

Cetacea,

Odontoceti,

homodont,

Early Miocene,

Peru,

phylogeny,

new genus, new species. and Macrodelphinus. Our phylogenetic analysis, based on 77 characters for 35 odontocete taxa, suggests the existence of an early Miocene Eastern Pacific long-snouted homodont odontocete clade (with an hypothetical South Atlantic member, the poorly known Argyrocetus patagonicus Lydekker, 1893), distinct from the only superficially similar eoplatanistids and eurhinodelphinids. Furthermore, our consensus tree indicates an early branching of this new clade compared to other homodont odontocete lineages. Unfortunately, the results of the cladistic analysis presented here are not well supported; a reappraisal of Argyrocetus and Macrodelphinus is needed to more clearly define the new clade and bolster its phylogentic position. 
MOTS CLÉS

Cetacea,

Odontoceti,

homodonte,

Miocène inférieur,

Pérou,

phylogénie

genre nouveau, espèce nouvelle.

\section{RÉSUMÉ}

Un nouveau cétacé à dents (Mammalia, Cetacea, Odontoceti) archaïque homodonte du Miocène inférieur du Pérou. À quelques exceptions près, les odontocètes (cétacés à dents) actuels possèdent une dentition approximativement homodonte. Le passage de dents de type basilosauridé à racine double et munies de denticules accessoires à des dents coniques à racine simple s'est produit au cours de l'Oligocène supérieur-Miocène inférieur. À cette époque, plusieurs clades d'odontocètes homodontes et majoritairement longirostres apparaissent dans le registre fossile. Parmi ceux-ci, les espèces des genres Argyrocetus Lydekker, 1893 et Macrodelphinus Wilson, 1935, du Miocène inférieur du Pacifique Nord-Est et d'Argentine, ont été attribuées à titre d'essai à la famille Eurhinodelphinidae. Cependant, à cause de l'état fragmentaire des spécimens, aucune apomorphie non-ambigüe de la famille n'a pu être détectée. Sur base de deux crânes bien préservés, associés à des éléments de mandibule, découverts dans les couches du Miocène inférieur de la Formation Chilcatay (Bassin Pisco, Pérou), nous rendons compte d'un nouveau genre et d'une nouvelle espèce d'odontocète longirostre et homodonte, Chilcacetus cavirhinus n. gen., n. sp. Caractérisé entre autres par la présence d'alvéoles dans la partie prémaxillaire du rostre, l'absence d'un sillon latéral sur le rostre, des nasaux élevés antérodorsalement, une cavité entre nasaux et mésethmoïde sur la paroi latérale des narines osseuses (peut-être autapomorphique), une fosse temporale élevée, et l'absence d'ankylose de la symphyse mandibulaire, C. cavirhinus n. gen., n. sp. ne rentre dans aucune des familles connues d'odontocètes mais partage plusieurs traits morphologiques avec Argyrocetus spp. et Macrodelphinus. Notre analyse phylogénétique, appliquant 77 caractères à 35 taxons d'odontocètes, suggère l'existence d'un clade de dauphins longirostres homodontes dans le Pacifique Est (avec un membre hypothétique dans l'Atlantique Sud, le mal connu Argyrocetus patagonicus Lydekker, 1893), bien distinct des superficiellement similaires éoplatanistidés et eurhinodelphinidés. De plus, l'arbre de consensus indique le branchement précoce du nouveau clade par rapport aux autres lignées d'odontocètes homodontes. Malheureusement, les résultats de l'analyse cladistique sont relativement faiblement soutenus; une réévaluation des genres Argyrocetus et Macrodelphinus est nécessaire pour mieux définir ce nouveau clade et le positionner de façon plus robuste dans un cadre phylogénétique.

\section{INTRODUCTION}

Apart from minor morphological differences between anterior and posterior teeth in a few species (e.g., the river dolphins Inia (d'Orbigny, 1834) and Platanista (Wagler, 1830)), extant toothed cetaceans (suborder Odontoceti) are generally considered homodont, with much less change along the tooth row than in basilosaurid archaeocetes, the latter being characterized by double-rooted cheek teeth with transversely flattened crowns bearing accessory denticles. Several families of heterodont odontocetes (Agorophiidae, Simocetidae, Squalodontidae, Waipatiidae, and Xenorophidae), dating from the Oligocene and early to middle Miocene, are currently known; these are considered morphologically and phylogenetically intermediary between basilosaurid archaeocetes and extant homodont odontocete families (Muizon 1991; Fordyce 1994, 2002; Uhen 2008; Geisler et al. 2011). During the late Oligocene-early Miocene, several groups of now extinct roughly homodont odontocetes arose, including Allodelphinidae, Eoplatanistidae, Eurinodelphinidae, the probably nonmonophyletic Kentriodontidae, the platanistid subfamily Pomatodelphininae, and Squalodelphinidae (Fordyce \& Muizon 2001). Except for squalodelphinids and most of the kentriodontids, these clades are characterized by a par- ticularly elongated snout bearing numerous, proportionally small teeth. Hypotheses concerning the phylogenetic relationships of these long-snouted dolphins with extant families have been proposed, but as yet no consensus has emerged, in part because some taxa were not included in large cladistic analyses (e.g., Muizon 1991; Fordyce 1994; Geisler \& Sanders 2003; Lambert 2005a; Barnes 2006; Geisler et al. 2011; Aguirre-Fernández \& Fordyce 2014; Lambert et al. 2014). Furthermore, among the early Miocene long-snouted forms, the familial affinities of several other taxa are still debated. Indeed, due to the fragmentary state of the type series, relationships of members of the genera Argyrocetus Lydekker, 1893 (three species from the Northeast Pacific and Argentina) and Macrodelphinus Wilson, 1935 (one species from the Northeast Pacific) are not convincingly resolved (Kellogg 1932; Wilson 1935; Barnes 1976; Lambert 2005b).

Based on two skulls from the early Miocene of the Pisco Basin (Peru), here we describe a new genus and species of homodont long-snouted odontocete, sharing morphological similarities with Macrodelphinus and species of the genus Argyrocetus. Better preserved than published specimens of these two genera, the new taxon helps resolve their relationships and contributes to filling in the gap(s) between early, heterodont, odontocetes, and extant families. 


\section{MATERIAL AND METHODS}

\section{ABBREVIATIONS}

BDNLTM Bünde Doberg und Tabak Museum, Bünde, Germany; IRSNB Institut Royal des Sciences Naturelles de Belgique, Brussels, Belgium;

LACM Natural History Museum of Los Angeles County, Los Angeles, USA;

MGP Museo di Geologia e Paleontologia, Università di Padova, Italy;

MLP Museo de La Plata, La Plata, Argentina;

MNHL Muséum d'Histoire naturelle de Lyon, France;

MNHN Muséum national d'Histoire naturelle, Paris, France;

MSNUP Museo di Storia Naturale, Università di Pisa, Italy;

MUSM Museo de Historia Natural, Universidad Nacional Mayor de San Marco, Lima, Peru;

MZUF Museo di Zoologia, Università di Firenze, Italy;

NNML Nationaal Natuurhistorisch Museum Naturalis, Leiden, The Netherlands;

RMNH Naturalis, Leiden, The Netherlands;

SAM Iziko South African Museum, Cape Town, South Africa;

USNM National Museum of Natural History, Smithsonian Institution, Washington D.C., USA;

YPM Yale Peabody Museum, New Haven, Connecticut, USA;

ZMA Zoölogisch Museum Amsterdam, The Netherlands.

\section{SPECIMENS}

During early steps of the preparation and study of the specimen MNHN.F.PRU11 described here (Macé et al. 1999), ear bones were unfortunately lost. In the following description, the illustrations of the ear bones were redrawn from those of a preliminary manuscript; these illustrations represent our only documentation for these highly diagnostic bones. Therefore, the few characters that we could extract from these illustrations cannot be checked in reference to the original specimen. We acknowledge this problematic situation, but we think nevertheless that these data are worth including in our description of the new taxon.

A list of the specimens examined for this study is given in Appendix 1.

\section{TERMINOLOGY}

For the terminology of skull bones, we mostly follow Mead \& Fordyce (2009).

REMARK ON THE SYSTEMATICS OF THE GENUS ARGYROCETUS As mentioned in an earlier work (Lambert 2005b), the attribution to the genus Argyrocetus of the Californian species 'A.' joaquinensis Kellogg, 1932 and 'A.' bakersfieldensis (Wilson, 1935) has not been resolved due mainly to the fragmentary condition of the holotype of the Argentinian type species A. patagonicus Lydekker, 1893. Because the type material of the Californian species also consists of partial skulls, with no described ear bones, the familial affinities of these taxa are currently not satisfactorily resolved (see discussion below). Therefore, we prefer to keep the genus name between quotation marks for the two Californian species, pending the description of more complete specimens for the three taxa.

\section{SYSTEMATIC PALAEONTOLOGY}

\author{
Order CETACEA Brisson, 1762 \\ Suborder ODONTOCETI Flower, 1867 \\ Family incertae sedis
}

Genus Chilcacetus n. gen.

TYPe AND ONLY SPECIES. - Chilcacetus cavirhinus $\mathrm{n}$. sp.

ETYMOlogy. - From Chilcatay, the geological formation from which the holotype and referred specimen originate, and "cetus", whale in Latin.

DiAgNosis. - The diagnosis of the genus is the same as for the only species, Chilcacetus cavirbinus n. gen., n. sp.

\section{Chilcacetus cavirhinus $\mathrm{n}$. sp.}

(Figs 1-12; Tables 1, 2)

HOLOTYPE. - MNHN.F.PRU11, a nearly complete skull only lacking the anterior part of the rostrum and the ventral-most region of the basicranium, with the associated right mandible (anterior end missing), and the manubrium (or presternum). The right periotic and tympanic bulla, as well as the left periotic were originally present; unfortunately they were lost at an early stage of the preparation of the skull and mandible (see comment above).

REFERRED SPECIMEN. - MUSM 1401, a nearly complete skull, only lacking fragments of the supraorbital processes and the ventral-most part of the basicranium (including the earbones), and with most of the ventral surface heavily abraded, with associated fragments of both mandibles, eight partly preserved vertebrae, and rib fragments. Locality of Ullujaya (see below). Approximate geographic coordinates: $14^{\circ} 34^{\prime} \mathrm{S}-75^{\circ} 38^{\prime} \mathrm{W}$.

ETymology. - From "cavi", hole, cavity, and "rhinus", nose in Latin. A reference to the excavation between nasals and mesethmoid along the nasal tracts observed in the new species.

TYPe LOCAliTY. - The holotype was collected in 1988 close to Ullujaya, Pisco Basin, Peru, a few kilometers south of where the referred specimen MUSM 1401 was recovered. Approximate geographic coordinates: $14^{\circ} 37^{\prime} \mathrm{S}-75^{\circ} 38^{\prime} 20^{\prime \prime} \mathrm{W}$.

TYPE HORIZON AND AGE. - Chilcatay Formation, latest Oligocene to early Miocene (Dunbar et al. 1990; DeVries 1998, 2001). Although the precise locality of the holotype is unknown, the referred specimen MUSM 1401 originates from within the Chilcatay Formation, several meters under the Chilcatay Formation - Pisco Formation disconformity, at Ullujaya, a few kilometers north to the type locality. Based on a published section a short distance from Ullujaya, the Chilcatay Formation layers of this locality (which preserves the fossilized remains of other marine vertebrates including mysticetes, kentriodontids, the squalodelphinids Huaridelphis raimondii Lambert, Bianucci \& Urbina, 2014 and Notocetus vanbenedeni Moreno, 1892, and a stem physeteroid) are tentatively dated to the early Miocene (Alván De la Cruz 2008; Lambert et al. 2014; Bianucci et al. 2015).

Diagnosis. - Chilcacetus cavirhinus n. gen., n. sp. is a longsnouted homodont odontocete (ratio between rostrum length and condylobasal length $>0.70$ ) differing from all other odontocetes in the presence of a cavity between nasals and mesethmoid on the posterior wall of the bony nares. It differs from members of other long-snouted homodont extinct families (Allodelphinidae, Eoplatanistidae, Eurhinodelphinidae, and Platanistidae) in the absence of a deep lateral groove along the rostrum and in the absence of ankylosis for the symphysis of the mandibles. 
TABLE 1. - Skull measurements (in millimeters) for the holotype MNHN.F.PRU11 and referred specimen MUSM 1401 of Chilcacetus cavirhinus n. gen., n. sp. Abbreviations: e, estimate; +, incomplete; -, missing data.

\begin{tabular}{|c|c|c|}
\hline & $\begin{array}{c}\text { MNHN.F.PRU11 } \\
\text { (holotype) }\end{array}$ & MUSM 1401 \\
\hline Condylobasal length & +572 & 852 \\
\hline Rostrum length & +340 & 611 \\
\hline Maximum width of mesorostral groove on the rostrum & 20 & 17 \\
\hline Width of rostrum at base & 146 & 158 \\
\hline Width of premaxillae at rostrum base & 89 & 92 \\
\hline Width of mesorostral groove at rostrum base & 19.5 & 16.5 \\
\hline Distance between anterior tips of right and left premaxillary foramina & 48.5 & 60.5 \\
\hline Preorbital width & 221 & e228 \\
\hline Postorbital width & 250 & - \\
\hline Minimum distance between premaxillae anterior to bony nares & 10 & 14 \\
\hline Distance between first posterior alveolus and antorbital notch & 45.5 & 68 \\
\hline Maximum width of premaxillae on cranium & 109 & 108.5 \\
\hline Width of right premaxillary sac fossa & 45 & 47 \\
\hline Width of left premaxillary sac fossa & 48 & 45 \\
\hline Width of bony nares & 42.5 & 46 \\
\hline Maximum width of nasals & 63 & 61 \\
\hline Length of medial suture of nasals & +15.5 & 19 \\
\hline Distance between lateral margins of premaxillae on vertex & 84 & 77 \\
\hline Minimum distance between maxillae across vertex & 64 & 53.5 \\
\hline Maximum length of frontals on vertex & e37 & 25 \\
\hline Distance between anteromedial point of nasals and supraoccipital & +52 & 43 \\
\hline Bizygomatic width & e246 & +271 \\
\hline Width between posterodorsal corners of temporal fossae & 152 & 154 \\
\hline Minimum posterior distance between temporal fossae & 131 & 106 \\
\hline Length of right orbit & 78 & - \\
\hline Length of left orbit & e76 & - \\
\hline Height of right postorbital process of frontal & 38 & - \\
\hline Height of right temporal fossa & 77 & 89 \\
\hline Height of left temporal fossa & 75 & 91 \\
\hline Length of right temporal fossa & e121 & - \\
\hline Length of left temporal fossa & 126 & - \\
\hline Width of occipital condyles & 95 & 93 \\
\hline Height of right occipital condyle & 47 & +41 \\
\hline Width of right occipital condyle & 28 & 29 \\
\hline Width of foramen magnum & e43 & e44 \\
\hline Maximum distance between basioccipital crests & +98 & +109 \\
\hline Maximum distance between lateral margins of exoccipitals & +207 & 241 \\
\hline Longitudinal distance between anterior apex of left palatine and level of left antorbital notch & 35 & - \\
\hline Distance between anterior apex of left palatine and apex of left pterygoid & 49 & - \\
\hline Distance between anterior apex of left pterygoid and apex of left hamular process & 79 & - \\
\hline Maximum width of hamular processes & e48 & - \\
\hline
\end{tabular}

It further differs from Eurhinodelphinidae in lacking an extended edentulous anterior premaxillary portion of the rostrum, in the nasals partly overhanging the bony nares, in the more anteriorly elongated zygomatic process of the squamosal (ratio between the height of the process and the length of the process $\geq 1.10$ ), in the cranium distinctly longer than wide, in the lesser transverse widening of the supraoccipital shield (ratio between the maximum width of the supraoccipital at the lateral corners of the nuchal crest and the postorbital width $<0.70$ ), in the posterior margin of the postorbital process being vertical, in the top of the temporal fossa being nearly as high as the nuchal crest, in the palatines being separated anteromedially for a long distance at rostrum base, and in the longer and more laterally directed posterior process of the periotic. It differs from Eoplatanistidae in the premaxillary foramen roughly at the level of the antorbital notch, in the thinner and flatter antorbital process, in the acute anterior margin of the nasal partly overhanging the bony nares, in the transversely concave and less anteriorly projected anterodorsal portion of the supraoccipital shield, in the deep anterior bullar facet of the periotic, in the elongated posterior process of the periotic, and in bearing a conspicuous median furrow on the tympanic bulla. It differs from Argyrocetus patagonicus in the reduced widening of the premaxillae at the rostrum base, in lacking a wide dorsal opening of the mesorostral groove, in the premaxillary foramen roughly at the level of the antorbital notch, in the angle formed by the basioccipital crests in ventral view < $50^{\circ}$, in the top of the temporal fossa being nearly as high as the nuchal crest, and in the absence of ankylosis for the symphysis of the mandibles. It differs from 'Argyrocetus' bakersfieldensis in lacking a deep lateral groove on the rostrum, in lacking a deep sulcus anterior to the main dorsal infraorbital foramen at rostrum base, and in the palatines being separated anteromedially for a long distance at rostrum base. It differs from 'Argyrocetus' joaquinensis in the dorsal opening of the mesorostral groove anterior to the rostrum base narrower than the premaxilla, in the presence of more than one dorsal infraorbital foramen at rostrum base, in lacking a deep sulcus anterior to the main dorsal infraorbital foramen at rostrum base, in the proportionally shorter and wider nasal, in the nasal partly overhanging the bony nares, in the wide exposure of the frontal on the vertex, in the posterior margin of the postorbital process being vertical, in the palatines separated anteromedially for a longer distance at rostrum base, in the significantly shorter hamular process of the pterygoid, and in the ventral margin of the postglenoid process of the squamosal being approximately at the same level as the ventral margin of the exoccipital in lateral view. It differs from Macrodelphinus in its smaller size, in the premaxillary portion of the rostrum making less than 10 per cent of its total 
A

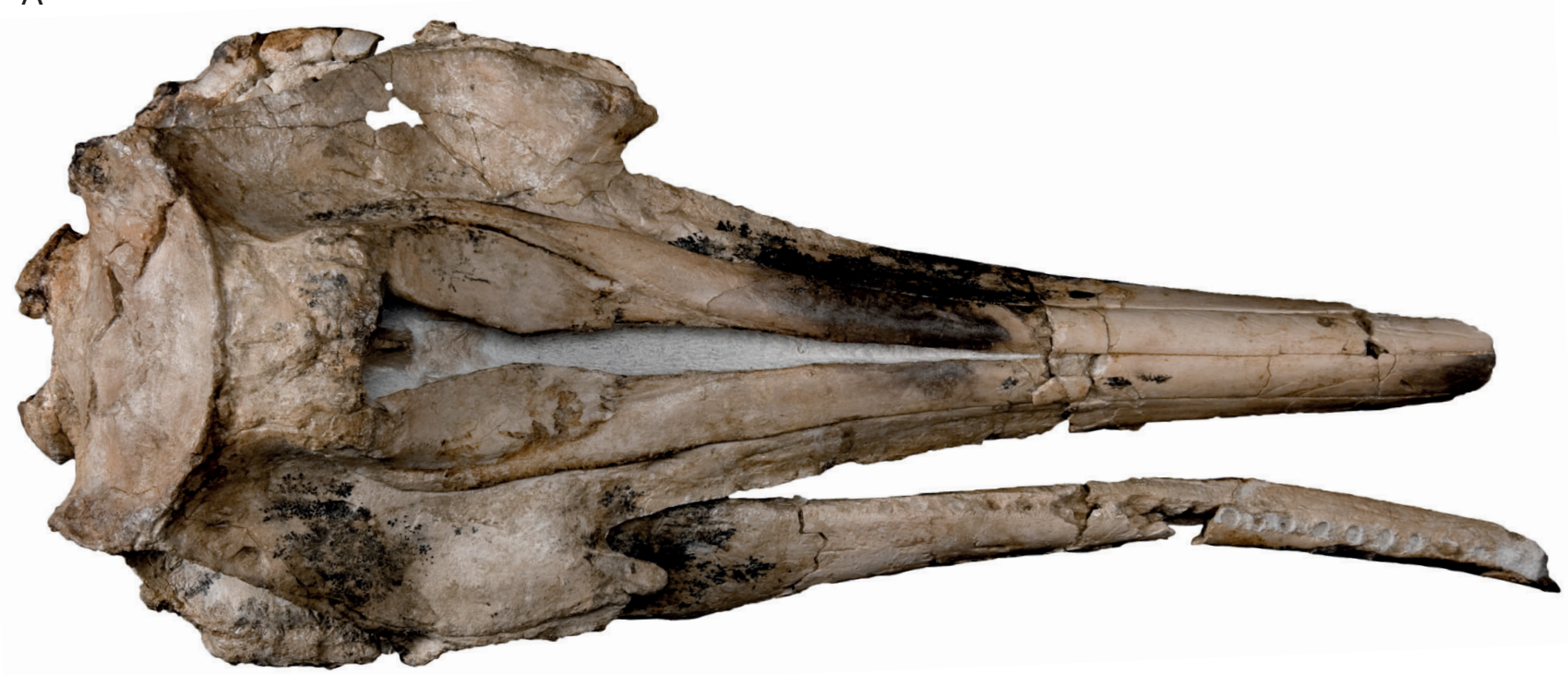

B

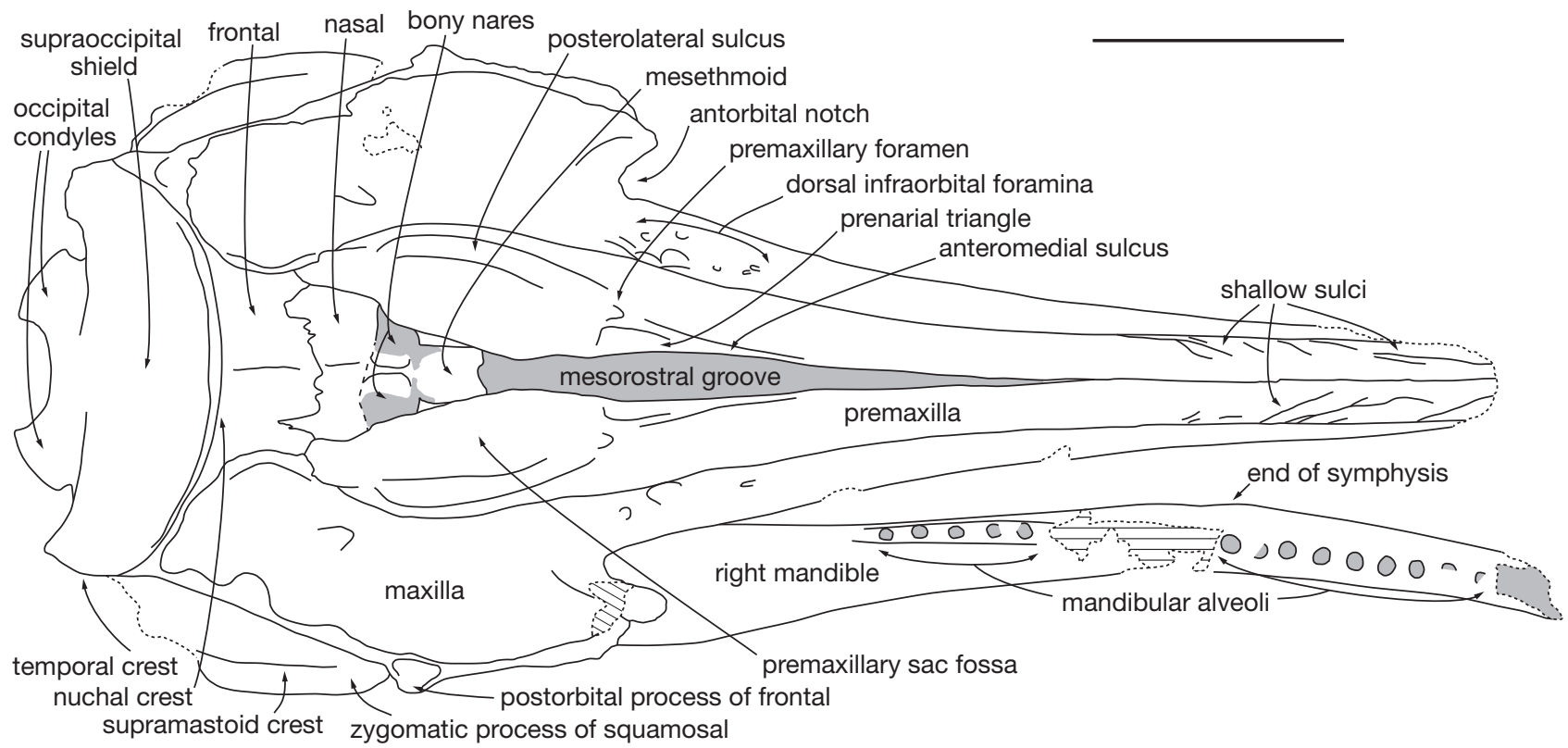

FIG. 1. - Skull and part of right mandible of Chilcacetus cavirhinus n. gen., n. sp., MNHN.F.PRU11 (holotype), in dorsal view: A, photograph; B, interpretive drawing. Hatching for surfaces of break; dashed line for incomplete elements; shading for sediment. Scale bar: $100 \mathrm{~mm}$.

length, in the premaxillary foramen roughly at the level of the antorbital notch, in the nasal proportionally longer compared to the frontal on the vertex, in the palatines separated anteromedially for a long distance at rostrum base. It differs from Papahu AguirreFernández \& Fordyce, 2014 in the rostrum being proportionally dorsoventrally thicker in its proximal part, in the single premaxillary foramen roughly at the level of the antorbital notch, in the dorsal exposure of the premaxilla wider than the exposure of the maxilla at rostrum base, in the proportionally wider ascending process of the premaxilla, in the anterodorsal elevation of the dorsal surface of the nasal, in the posterolateral projection of the nasal, in the elongate postorbital process of the frontal, in the long and deeper anterior bulla facet of the periotic, in the posterior elevation of the dorsal margin of the mandible being progressive.

It differs from Platanistidae and Squalodelphinidae in that its cranium is as long as wide, in lacking a deep medial depression in the dorsal surface of the premaxillae at rostrum base, in the posterior dorsal infraorbital foramen being lateral to the lateral margin of the premaxillary sac fossa, in the nasal rising anterodorsally and partly overhanging the bony nares, in the strong reduction of the lateral lamina of the pterygoid, in the absence of an extension of the pterygoid sinus in the orbit roof; in the zygomatic process of the squamosal not being dorsoventrally inflated, in the proportionally longer posterior process of the periotic, in lacking an individualized anterior spine on the tympanic, and in the lower involucrum of the tympanic in medial view, cut by an indentation at mid-length. It further differs from Platanistidae in lacking a dorsal crest on the antorbital process. It differs from Allodelphinidae in lacking a deep medial depression in the dorsal surface of the premaxillae at rostrum base, in the cranium as long as wide, in the proportionally wider vertex, in the strong reduction of the lateral lamina of the pterygoid, in the anteriorly long zygomatic process of the squamosal, and in the top of the temporal fossa being nearly as high as the nuchal crest. 

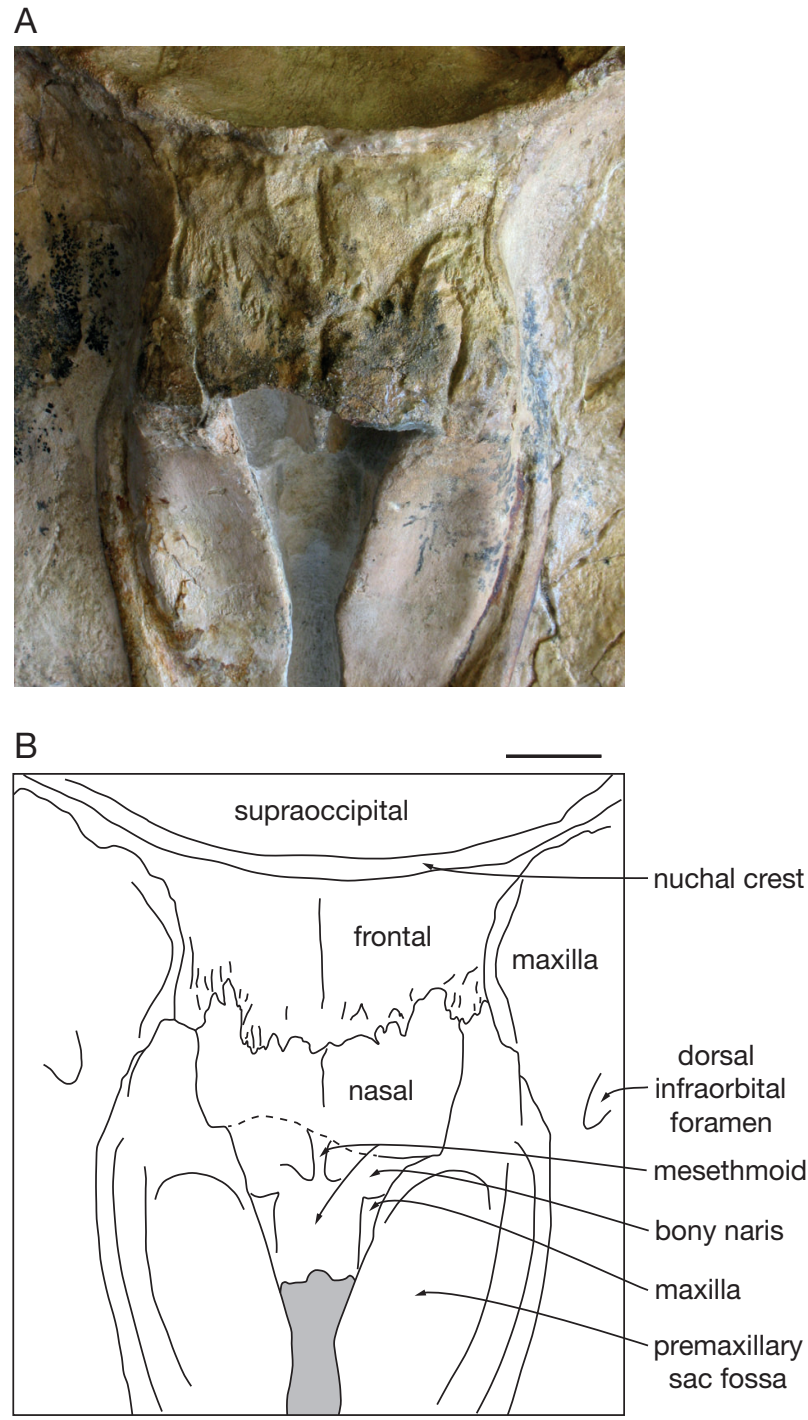

FIG. 2. - Detail of the vertex of the skull of Chilcacetus cavirhinus n. gen., n. sp. MNHN.F.PRU11 (holotype), in dorsal view: A, photograph; B, interpretive drawing. Dashed line for incomplete elements; shading for sediment. Scale bar: $20 \mathrm{~mm}$.

\section{DESCRIPTION}

Skull

The holotype MNHN.F.PRU11 (Figs 1-10) and MUSM 1401 (Figs $11 ; 12$ ) have a medium size skull, with a postorbital width of $250 \mathrm{~mm}$ in the holotype and a width across the occipital condyles of 95 and $93 \mathrm{~mm}$ respectively (see Table 1). Except for the vertex and the supraoccipital shield (see below), measurements in MUSM 1401 are generally slightly greater than in the holotype. The sutures between the well-ossified cranial bones are closed, with no indication of movement for individual bones, and the maxillary alveoli are ossified, suggesting adult individuals. The complete rostrum of MUSM 1401 is long, comprising $72 \%$ of the condylobasal length. Furthermore, the width of the base of the rostrum is slightly greater than in the holotype (Table 1). On the anterior part of the rostrum, transverse sections have a semi-circular outline, with the dorsal surface regularly convex (Fig. 11G). Based on the outline of the section of the premaxillae and maxillae at
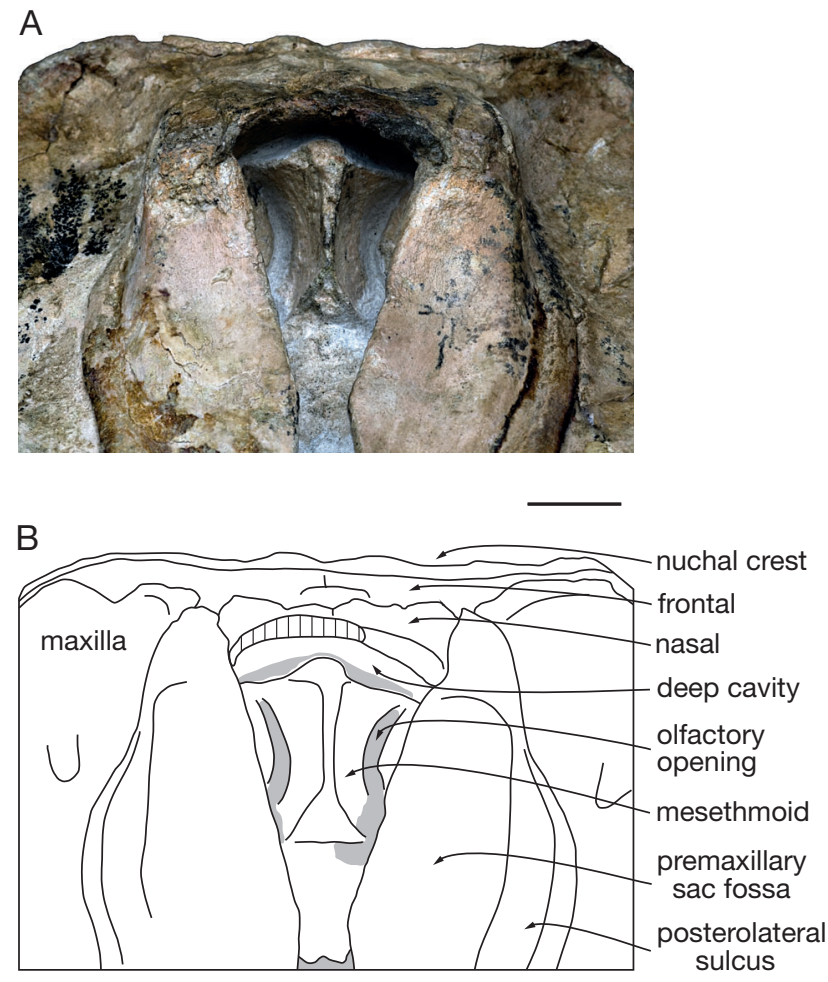

FIG. 3. - Detail of the vertex of the skull of Chilcacetus cavirhinus n. gen., n. sp., MNHN.F.PRU11 (holotype), in anterodorsal view: A, photograph; $\mathbf{B}$, interpretive drawing. Hatching for surfaces of break; shading for sediment. Scale bar: $20 \mathrm{~mm}$.

the preserved apex of the holotype, it is likely that its rostrum was originally similarly long. The brain cavity is somewhat dorsoventrally crushed in both specimens, as indicated by horizontal cracks in the supraoccipital shield and the medial wall of the temporal fossae. The cranium is nearly as wide as long, with a weakly elevated vertex (ratio between vertical distance from dorsal margin of rostrum to top of vertex and width of the premaxillary sac fossae $<0.70$ ). The lateral edge of the frontal, posterior to the postorbital process is rectilinear and oblique. Dorsally, it does not fully cover the long and high, drop-shaped temporal fossa and consequently, most of the zygomatic process of the squamosal is exposed in dorsal view. This condition results in the facial region of Chilcacetus n. gen. being roughly trapezoidal (rather than semicircular or subrectangular), which is observed in several ancient odontocetes (e.g., Papahu, Prosqualodon Lydekker, 1893, Squalodon Grateloup, 1840, Squaloziphius Muizon, 1991, and Waipatia Fordyce, 1994), but not in eurhinodelphinids.

Premaxilla. As mentioned above, the anterior transverse section of the rostrum is nearly semicircular. The transversely convex premaxillae contact each other dorsomedially in the holotype, whereas the mesorostral groove is not completely roofed dorsally in MUSM 1401, retaining a dorsomedial opening along its whole extent. The medial contact in the holotype was likely not sutural, as indicated by a minor overlap of the right premaxilla by the left. In MUSM 1401, a longitudinal sulcus marks the dorsal surface of the distal portion of each 
A

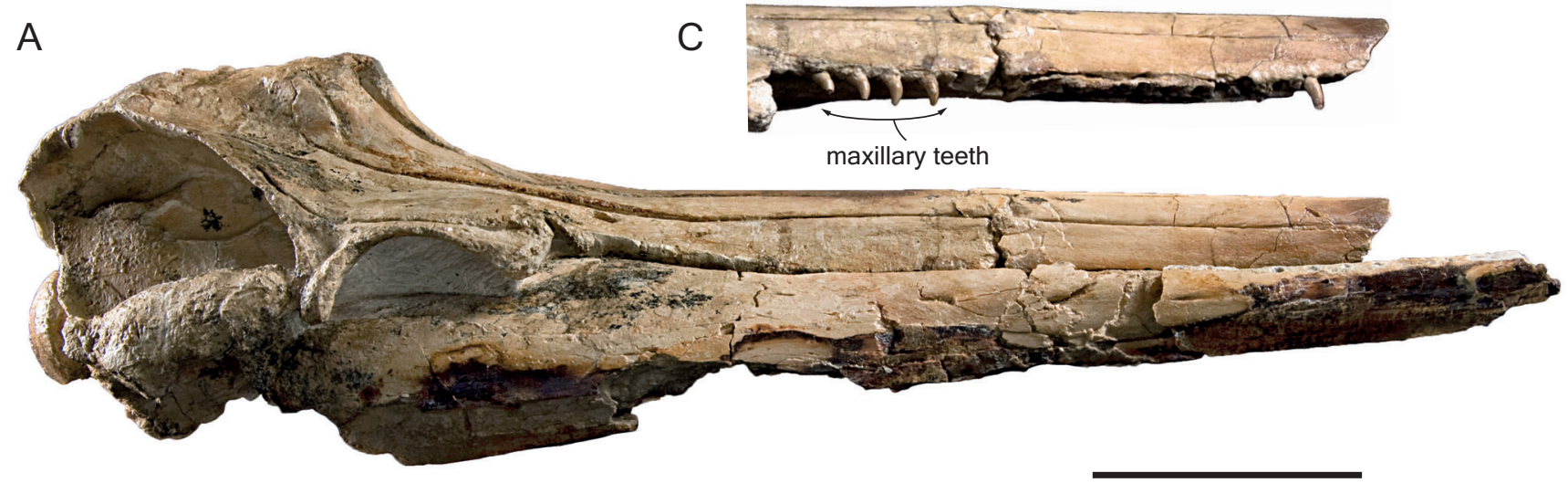

B

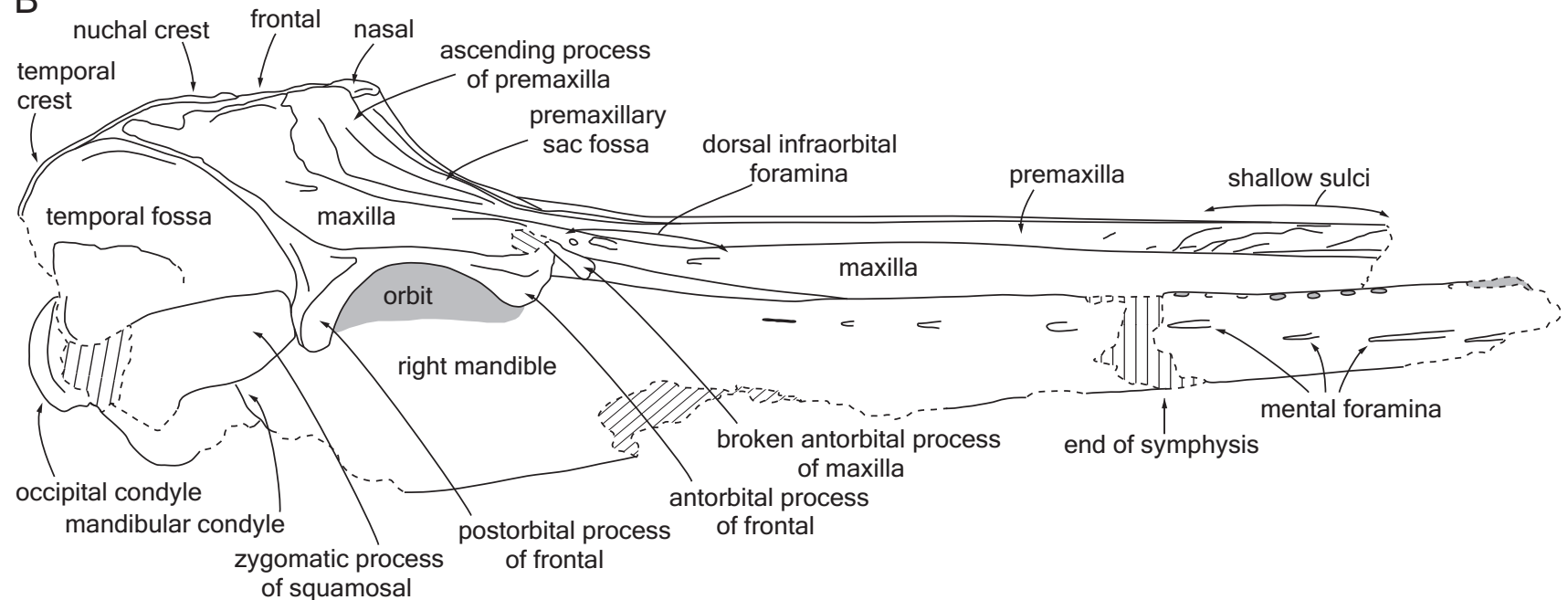

FIG. 4. - Skull and part of right mandible of Chilcacetus cavirhinus n. gen., n. sp. MNHN.F.PRU11 (holotype), in right lateral view: A, photograph; B, interpretive drawing; $\mathbf{C}$, detail of the anterior part of the rostrum with the anterior portion of the right mandible removed. Hatching for surfaces of break; dashed line for incomplete elements; shading for sediment. Scale bar: $100 \mathrm{~mm}$.

premaxilla, for about $150 \mathrm{~mm}$. The premaxilla-maxilla suture is discernible on the lateral surface of the rostrum of MUSM 1401 until a level $130 \mathrm{~mm}$ from the apex (Fig. 11B). Considering the eroded ventral surface of the maxillae, the distal premaxillary portion of the rostrum likely did not exceed $100 \mathrm{~mm}$. Furthermore alveoli are present in the alveolar groove to the end of the rostrum (Fig. 11C). This condition, also observed in the holotype of Macrodelphinus kelloggi Wilson, 1935 (at least 7 distinct alveoli in the premaxillary portion of the rostrum), is a major difference with eurhinodelphinids, characterized by a long premaxillary portion of the rostrum lacking alveoli (Muizon 1991; Lambert 2004, $2005 a, b)$. The number of alveoli in the premaxilla of MUSM 1401 cannot be determined precisely, due to the obscured end of the premaxilla-maxilla suture. The orientation of these anterior alveoli indicates that the anterior-most teeth were not procumbent in Chilcacetus cavirhinus n. gen., n. sp. In the holotype, the dorsolateral surface of the premaxilla is covered with shallow convoluted sulci for the distal $150 \mathrm{~mm}$ anteriorly; these sulci course anterodorsally from the maxillapremaxilla suture (Fig. 1). As in Macrodelphinus, this suture is not margined by a lateral groove in either specimen, differing from allodelphinids, eoplatanistids, eurhinodelphinids, and platanistids. Only a few foramina and short sulci are preserved along the premaxilla-maxilla suture of MUSM 1401. In lateral view, this suture raises distinctly backwards until about the midpoint in the length of the rostrum. Consequently, the lateral exposure of the premaxilla is reduced at this level, in association with its narrower dorsal exposure. From this midpoint, the progressively diverging premaxillae flatten and widen towards the base of the rostrum.

A slight concavity of the lateral margin of each premaxilla is observed a few centimeters anterior to the premaxillary foramen in both specimens. Situated at the level of the antorbital notches, the premaxillary foramen is approximately centered on the premaxilla of the holotype, whereas it is closer to the maxilla in MUSM 1401. The anterior-most premaxillary foramen is more anterior in Eoplatanista Dal Piaz, 1916, Papahu, Squalodon and Waipatia, whereas it is more posterior in Argyrocetus patagonicus and Macrodelphinus. The narrow anteromedial sulcus margins laterally the elongated prenarial triangle, whereas the wide posterolateral sulcus extends beyond the posterior margin of the bony nares, rising high along the lateral surface of the ascending process of the premaxilla. The shallow posteromedial sulcus is barely visible. The maximum opening of the mesorostral groove is in front of the level of 
the premaxillary foramina in the holotype, and slightly more anterior in MUSM 1401. In A. patagonicus, the dorsal opening of the groove is much wider, a feature possibly accentuated by dorsoventral crushing of the rostrum (Cabrera 1926). Furthermore, in the latter the premaxillary sac fossae slope ventrolaterally. The anterior limit of the bony nares of Chilcacetus cavirhinus $\mathrm{n}$. gen., n. sp. is V-shaped, but poorly defined. The bony nares roughly end at the level of the middle of the orbit, where the medial edges of the premaxillae are clearly approximated and present a medial angulation. The surface of the premaxillary sac fossa is distinctly concave longitudinally. The transverse concavity is somewhat more pronounced in the holotype, with the depression extending posterodorsally beyond two thirds of the length of the bony nares. The left premaxillary sac fossa is slightly wider than the right fossa in the holotype, whereas the opposite is measured in MUSM 1401. However, these weak asymmetries (ratio between width of right and left premaxillary sac fossae 0.94 and 1.04 respectively) are not considered significant. The ascending process is longitudinally short, with an abrupt posterodorsal elevation. It is transversely wide (more so than in Papahu and Waipatia), individualized from the posterolateral plate of the premaxilla by the posterolateral sulcus. Nevertheless, the lateral margin of the ascending process does not overhang the maxilla. The ascending process is not marked by a longitudinal premaxillary cleft, differing from Papahu, Waipatia and several platanistids and squalodelphinids (Fordyce 1994; Lambert et al. 2014). On the vertex, the premaxilla is wide lateral to the nasal in the holotype. Our interpretation of the sutures of the vertex (Fig. 2), remaining conjectural due to the presence of numerous longitudinal grooves along the nasal-frontal suture, suggests a wide contact between premaxilla and frontal. A narrower and shorter posterior part of the premaxilla on the vertex is observed in MUSM 1401; in the latter the premaxilla-frontal contact is either reduced or absent.

Maxilla. At the preserved apex of the rostrum of the holotype, the laterally facing exposure of the maxilla has roughly the same height as the premaxilla. As previously mentioned, the suture between the two bones rises posteriorly, until a level where the ventrolateral margin of the maxilla starts its elevation towards the antorbital notch. On each maxilla of the holotype, one large dorsal infraorbital foramen, wider on the right side, is located anterior to the antorbital notch. This foramen, not followed anteriorly by a sulcus, is surrounded by at least 5-6 smaller foramina on the left side and at least 2-3 on the less well-preserved right side. Similar small dorsal infraorbital foramina are detected in MUSM 1401, six on the right maxilla and five on the left. Better preserved in the holotype, the antorbital notch is deep, U-shaped, with a long anterolateral projection of the maxilla on the antorbital process (Fig. 1), as also seen in Macrodelphinus. The right projection was likely broken and artificially slightly shifted forwards. Posterior and posterolateral to the notch, the dorsal surface of the maxilla is only slightly elevated, without a distinct maxillary crest, and remaining lower than the premaxilla. A dorsal infraorbital foramen is located close to the maxilla-premaxilla suture at the level of the posterior margin of the bony nares, posterior to the level of the postorbital process of the frontal. Above the temporal fossa the lateral margin of the maxilla is directed posteromedially, nearly reaching the supraoccipital at a level posterior to the anterior-most level of the nuchal crest. The medial wall of the maxilla along the vertex is more erect on the left side, whereas it displays a more pronounced transverse convexity on the right side.

On the anterior margin of the bony nares, each maxilla sends a triangular ventromedial projection towards the mesethmoid, closing anterolaterally the bony nares at a level dorsoventrally lower than the medial margin of the premaxilla.

From the apex of the complete rostrum of MUSM 1401, a total tooth count of 41 is estimated on the right side and more than 38 on the left (as mentioned above, an uncertain number of the anterior alveoli originate in the premaxilla) (Fig. 11C). All alveoli correspond to single-rooted teeth; their transverse diameters range from 6 to $8 \mathrm{~mm}$ and alveoli are separated by transverse septa of $3-4 \mathrm{~mm}$. In the holotype, 21-22 alveoli for single-rooted teeth are counted on $276 \mathrm{~mm}$ of the incomplete right maxillary alveolar groove, whereas 20 alveoli are counted along $239 \mathrm{~mm}$ of the left groove. The transverse diameter of the roughly circular alveoli ranges from 6 to $7.5 \mathrm{~mm}$ (except for the smaller posterior alveoli), with transverse septa 5-7 $\mathrm{mm}$ long. The last posterior alveolus is closer to the antorbital notch in the holotype than in MUSM 1401 (see Table 1). Small, circular to oval depressions posterolateral to each alveolus along the anterior half of the rostrum of the holotype (best seen on the left side) are interpreted as embrasure pits created by the apex of opposing teeth.

More completely preserved in the holotype, the vomerine trough is deep and wide, limited laterally by shallow sulci originating and passing forwards from two foramina located at about half the preserved length of the rostrum (Fig. 5C). At least two additional pairs of foramina are visible, the posteriormost being located at the anterior tip of the palatine-maxilla suture and corresponding to the major palatine foramina.

Between the palatine and the ventral infraorbital foramen, the ventral surface of the maxilla (and possibly the lateral-most part of the palatine) is crossed by an oblique crest, smoothly recurved anterolaterally in the rostrum base (Figs 6; 7). A similar crest is seen in various odontocete groups, including eurhinodelphinids (see Lambert 2005a for Eurhinodelphis cocheteuxi du Bus, 1867). This crest is interpreted as the anterior limit of an area of origin for the internal or external pterygoid muscles (two of the adductors of the mandible; see Fraser \& Purves 1960; Seagars 1982). Seagars (1982) found that the internal pterygoid muscle is the most powerful muscle for the closure of the jaws in several delphinids, including longsnouted forms with numerous teeth.

The ventral infraorbital foramen is elongated, oblique to the long axis of the skull. $25 \mathrm{~mm}$ posterior to its posterior end, close to the orbitosphenoid, a small foramen, followed anteriorly by a sulcus towards the infraorbital foramen, might correspond to the sphenopalatine foramen (Fig. 6). 
A
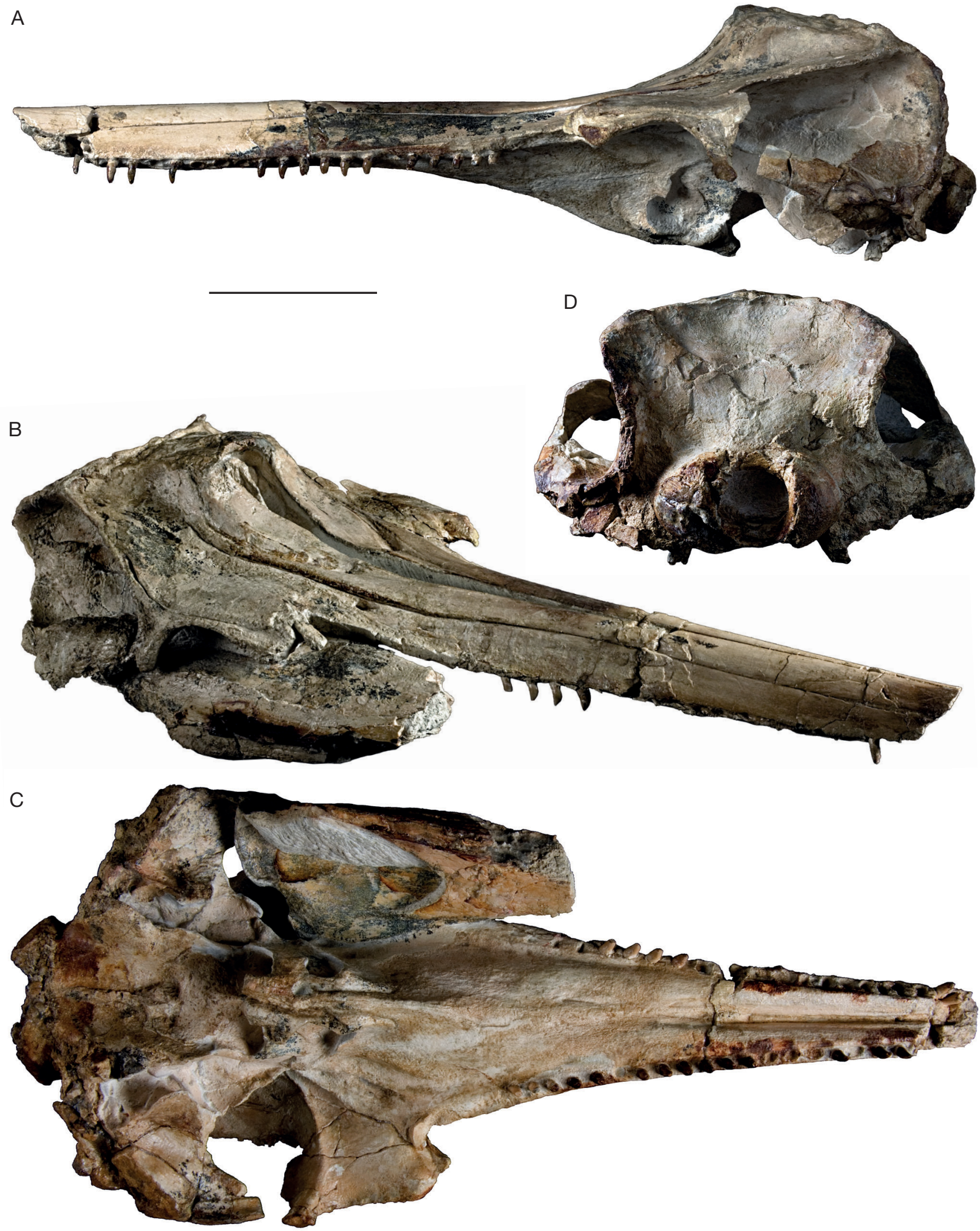

FIG. 5. - Skull and part of right mandible of Chilcacetus cavirhinus n. gen., n. sp., MNHN.F.PRU11 (holotype): A, left lateral view; B, oblique anterolateral and slightly dorsal view; C, ventral view; D, posterior view. Scale bar: $100 \mathrm{~mm}$. 
Mesethmoid. Between the triangular ventromedial projections of the maxillae on the anterior part of the bony nares of the holotype, the mesethmoid is visible as a low $30 \mathrm{~mm}$-long element with an irregular dorsal surface (Figs 2; 3). This region is separated from the keel of the nasal septum by an abrupt step; the empty space between the premaxillary sac fossae was likely originally occupied by cartilage. Completely hidden in dorsal view, due to the overhanging nasals, the posterior plate of the mesethmoid is excavated in both specimens by a pair of large crescent-like olfactory openings (Figs 3; 11D), as observed in many platanistoids (Hoch 2000; Godfrey 2013; Godfrey et al. 2013; Lambert et al. 2014), at least some eurhinodelphinids (e.g. Schizodelphis morckhoviensis du Bus, 1872; Lambert 2004), a specimen referred to 'Argyrocetus' bakersfieldensis (YPM 13410; Wilson 1935), Macrodelphinus (OL pers. obs.), and Waipatia (Fordyce 1994). A relatively large gap separates the upper margin of the mesethmoid plate from the smooth ventral surface of the nasals, forming a horizontal and transversely wide cavity on the posterior wall of the bony nares. Such a cavity is absent in 'Argyrocetus' joaquinensis and Macrodelphinus, and to our knowledge has not been described in any other odontocete. The dorsal surface of the mesethmoid plate is irregular in MUSM 1401, excavated by small fossae. The texture of this surface, reminiscent of the dorsal surface of the bony nasal septum, might indicate that the cavity between mesethmoid and nasal was originally filled with cartilage in Chilcacetus cavirhinus n. gen., n. sp.

Nasal. The nasals occupy a large surface on the vertex: they are anteroposteriorly shorter medially, due to the anteromedial projection of the frontals (Figs 2; 11E). Their lateral part extends farther posteriorly, even if their exact extent is difficult to determine due to the complex organization of the nasal-frontal suture; this is different from the condition in Papahu. At least in the holotype, the right nasal is narrower than the left, with a ratio between their respective maximum widths of 0.90 . The dorsal surface of each nasal rises gently anterodorsomedially, forming a convex dorsal outline in anterior view. Better preserved in MUSM 1401, the anterior margin of the joined nasals is regularly convex in dorsal view. Overhanging the bony nares, it forms an acute horizontal edge, with the ventral surface of the nasal progressively ascending forwards to the dorsal surface. A similar nasal morphology is seen in 'Argyrocetus' bakersfieldensis, 'A.' joaquinensis, and Macrodelphinus; it probably corresponds to a remnant of the primitive condition of the posteroventrally directed bony nares in archaic neocetes and archaeocetes (see Albertocetus Uhen, 2008 and Simocetus Fordyce, 2002). The nasals of the holotype and only referred specimen of Argyrocetus patagonicus are now lost (GB pers. obs.), but in the original illustrations (Lydekker 1893: pl. 5) they overhang the bony nares with an acute anterior margin, as clearly stated by the author. The nasals of Papahu and Waipatia are not as elevated anterodorsally, but the acute anterior margin similarly overhangs the bony nares (Fordyce 1994; Aguirre-Fernández \& Fordyce 2014). In some eurhinodelphinids, for example Ziphiodelpis abeli Dal Piaz in Bassani \& Misuri, 1912, the nasal is higher anteriorly, but it does not overhang the bony nares.
Frontal. On the vertex the frontal is slightly lower than the nasal, even if the presumed anteromedial corners of the joined frontals form a prominent region in the holotype. Based on our interpretation of the sutures of the holotype (Fig. 2), each frontal is wider on the vertex than the corresponding nasal. In MUSM 1401, displaying a significantly narrower vertex as demonstrated by the shorter distance between maxillae across the vertex, the nasal is slightly wider than the corresponding frontal. The anteroposterior extent of the frontal on the vertex is also shorter in MUSM 1401. The right frontal of the holotype is narrower than the left, with a ratio between the respective widths at mid-length of 0.84 . In the latter, the anterior part of the interfrontal suture and the internasal suture are shifted slightly to the left side as compared to the posterior end of the interfrontal suture. Posteriorly, the frontal is lower than the marked nuchal crest, comprised of the anteromedial margin of the supraoccipital.

The antorbital process of the frontal of the holotype is robust, triangular in lateral view (Figs 4; 5A), and partly exposed lateral to the maxilla in dorsal view. In lateral view, the medium size orbit displays a strongly concave outline, in relation with the ventrally long postorbital process (vertical length from the contact with the maxilla $=37 \mathrm{~mm}$, proportionally longer than in Papahu). The upper part of the lateral surface of the process is excavated by a triangular depression. The posterior margin of the process is roughly vertical. The contact with the zygomatic process of the squamosal, seen on the right side, is exaggerated to some degree by dorsoventral crushing of the cerebral cavity.

On the roof of the orbit, bordered posteriorly by the high medial portion of the infratemporal crest (= postorbital ridge), the frontal groove is directed posteromedially and slightly ventrally (Figs 5C; 6). In eurhinodelphinids, the groove is more transversely and ventrally directed. No trace could be found to indicate invasion of the orbit or temporal region of the frontal by the pterygoid sinus (see below for the alisphenoid and pterygoid limits of the sinus).

Supraoccipital. In dorsal view, the lateral extent of the supraoccipital shield is similar to the condition in 'Argyrocetus' bakersfieldensis and Eoplatanista, proportionally greater than in Squalodon and Waipatia, but less than in eurhinodelphinids. The outline of the acute nuchal crest is regularly convex anteriorly in dorsal view, limiting a transversely and longitudinally concave dorsal part of the supraoccipital shield. As in Macrodelphinus, the crest becomes thicker in the dorsolateral region where the surface of the supraoccipital shield is more uneven (Figs 1; 5D; 11A, F), likely for the insertion of neck muscles (possibly m. semispinalis or $\mathrm{m}$. rhomboideus sensu Schulte \& Smith 1918). From there, in the holotype the prominent descending temporal crest is directed posteriorly and slightly posteromedially, with the lateralmost surface of the supraoccipital facing posteromedially. In MUSM 1401, the temporal crest projects farther posteriorly (best seen in dorsal view; Fig. 11A). In posterior view the minimum distance between the temporal fossae across the supraoccipital shield is at mid-height of the temporal fossa; this distance is 
A
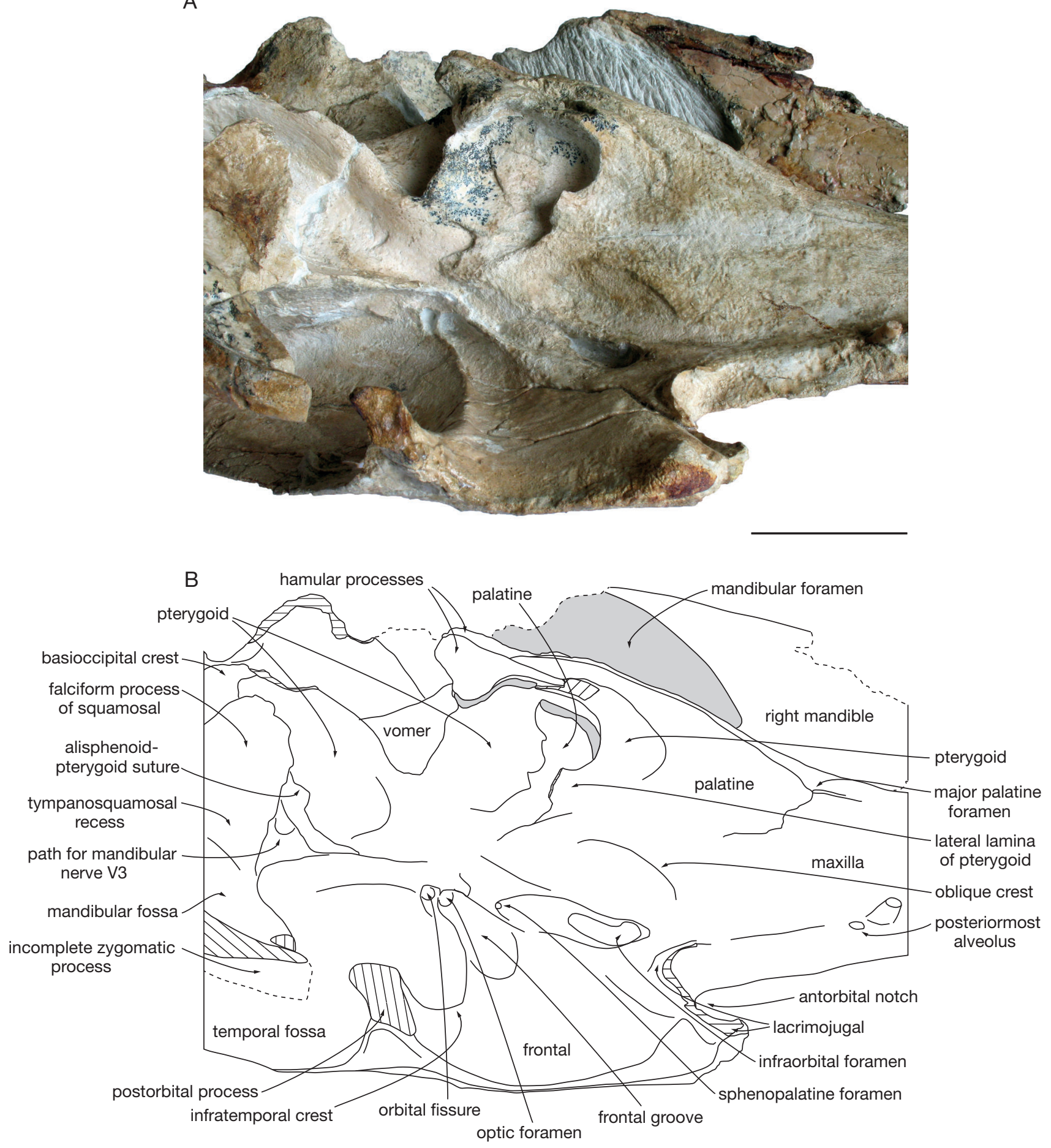

FIG. 6. - Detail of the left orbit and palate of the skull of Chilcacetus cavirhinus n. gen., n. sp., MNHN.F.PRU11 (holotype), in ventrolateral view: A, photograph; B, interpretive drawing. Hatching for surfaces of break; dashed line for incomplete elements; shading for sediment. Scale bar: $50 \mathrm{~mm}$.

greater in the holotype, which has a wider supraoccipital shield (Figs 5D; 11F). This difference between the two specimens may be partly explained by the degrees to which the skulls were crushed dorsoventrally.

Vomer. The mesorostral groove is partly filled with indurated sediment in both specimens, hiding the dorsal exposure of the vomer. In the deep vomerine trough, a keeled narrow stripe of the vomer is visible in ventral view. The vomer forms the medial and posterior walls of the choanae, reaching posteriorly to a level in line with the carotid foramen.

Palatine. The anterior tip of the palatine is $33 \mathrm{~mm}$ anterior to the antorbital notch in the holotype. From that level and 
for $40 \mathrm{~mm}$ backwards, left and right palatines are separated medially by a narrow exposure of the maxillae. The palatinemaxilla suture is more difficult to follow laterally; an interpretation based on the two sides is provided in Figure 7, with a posterolaterally and laterally directed suture. The palatine is exposed in the anterior portion of the pterygoid sinus fossa, in the part of the medial wall not covered by the pterygoid (Figs 6; 7), a condition also seen in Squaloziphius and several extant ziphiids (Lambert et al. 2013). The palatine part of the palate is distinctly keeled medially, contrasting with the lower palate of Squalodon, Squaloziphius, and Waipatia, possibly related to the elongated snout, as seen in Eoplatanista, eurhinodelphinids, and platanistids.

Pterygoid. The anterior end of the pterygoid is just posterior to the level of the antorbital notch; consequently the pterygoid sinus fossa, fully covered by the pterygoid at its anterior end, does not extend farther forward than the notch. The anteromedial margin of the pterygoid is prominent compared to the adjacent palatine; it becomes transversely thicker posteromedially, forming a wide shelf, triangular in ventral view, ventrally overhanging the anterior part of the pterygoid sinus fossa (Figs 5C; 6; 7). Following a transverse constriction, this medial wall of the pterygoid widens considerably for a short distance, until the anterior margin of the ventral choanae. From there, the bone tapers to form a short and robust hamular process, less than $20 \mathrm{~mm}$ long from the anterior limit of the choanae, along the sagittal plane of the skull. Similarly joined thick hamular processes, not excavated by the pterygoid sinus fossa, are observed, even if longer, in 'Argyrocetus' joaquinensis, Simocetus, and Squaloziphius (Kellogg 1932; Muizon 1991; Fordyce 2002). The medial lamina of the pterygoid forms the lateral wall of the choana. Posterior to the eustachian notch, it overlaps the basioccipital crest to the level of the carotid foramen. The lateral lamina of the pterygoid is preserved roughly to the same extent on both sides of the holotype, partly limiting laterally the transversely narrow pterygoid sinus fossa for only half the length of the fossa anterior to the choana. More posteriorly, the lateral lamina becomes a low and thin ridge along the subtemporal crest, joining the lateral margin of the alisphenoid (Fig. 7). Therefore, we consider that Chilcacetus cavirhinus n. gen., n. sp. did not possess a complete lateral lamina of the pterygoid contacting the falciform process of the squamosal, contrary to platanistids, squalodelphinids, and at least some eurhinodelphinids (e.g., Schizodelphis Gervais, 1861 and Xiphiacetus Lambert, 2005); a similar condition is proposed for Waipatia (Fordyce 1994). Along the medial wall of the thin ridge along the subtemporal crest described above, the pterygoid is excavated by a few small and shallow fossae, interpreted as extensions for the pterygoid sinus reminiscent of the condition in some ziphiids (e.g., Ninoziphius Muizon, 1983; Lambert et al. 2013). Dorsally, a thin plate of the pterygoid covers more than half the wide subcircular and concave area of the alisphenoid anterior to the foramen ovale; the alisphenoid is exposed mainly in the posterolateral portion of this depression for the pterygoid sinus.
Jugal/lacrimal. The left jugal-maxilla suture is visible posteromedially and medially to the antorbital notch (Fig. 6). The base of the styliform part of the jugal is preserved in section, forming the posteroventral wall of the antorbital notch. On the antorbital process, only an incomplete thin plate of the lacrimojugal is observed, ventrally lining the anteroventral margin of the maxilla. Based on the section of this preserved fragment and from the nature of the anteroventral surface of the frontal on the antorbital process, we suspect the lacrimojugal was originally shorter longitudinally than transversely wide, with an outline in ventral view similar, for example, to Waipatia (Fordyce 1994). In lateral view, the lacrimojugal was probably limited to the anteroventral side of the antorbital process of the frontal, not or only barely dorsally exposed, differing on that point from Waipatia. The posterior portion of the right styliform part of the jugal is preserved between the mandible and the zygomatic process of the squamosal; no significant thickening is observed at that level (Fig. 7).

Orbitosphenoid. The orbitosphenoid-frontal suture is difficult to follow, even if a thin plate along the anterior wall of the frontal groove likely corresponds to the former. At the end of the frontal groove, two main openings are observed. The slightly larger anterior opening, the origin and continuation of the frontal groove, is interpreted as the optic foramen, whereas the posterior opening is probably the orbital fissure (sphenoidal fissure, with superior and inferior fissures not distinguished), separated from the optic foramen by the metoptic process (Fig. 6). The foramen rotundum is not observed, either coalescent with the orbital fissure or obscured due to the slight dorsoventral crushing of this region.

Alisphenoid. In ventral view, the alisphenoid is exposed in the posterolateral part of the large subcircular depression (= part of the pterygoid sinus fossa) anterior to the foramen ovale, a feature seen in both specimens (Figs 7; 11C). The lateral extent of this depression is similar to the condition in Papahu and Waipatia (Fordyce 1994; Aguirre-Fernández \& Fordyce 2014). The lateral margin of the alisphenoid along the subtemporal crest bears a thin ridge that is a continuation of the ridge on the pterygoid, limiting the pterygoid sinus fossa laterally. This ridge turns posteriorly and posteromedially and forms the anterior wall of the path for the mandibular nerve $\mathrm{V} 3$ and of the foramen ovale. The latter is distinctly anterior to the level of the carotid foramen. The alisphenoid-squamosal suture is difficult to follow in the holotype. In MUSM 1401, the foramen ovale is separated from the posterior lacerate foramen by a strip of bone at least $18 \mathrm{~mm}$ wide. The greatest diameter of the posterior lacerate foramen is $20 \mathrm{~mm}$.

Squamosal. Relative to the long temporal fossa, the zygomatic process of the squamosal is elongate anteriorly, more so than in eurhinodelphinids, and only moderately elevated towards the postorbital process of the frontal (Figs 4; 5A; 11B). Its dorsal margin is longitudinally convex and transversely thick. This margin dips smoothly towards the floor of the temporal fossa, lacking the posterior elevation seen in physeteroids. 

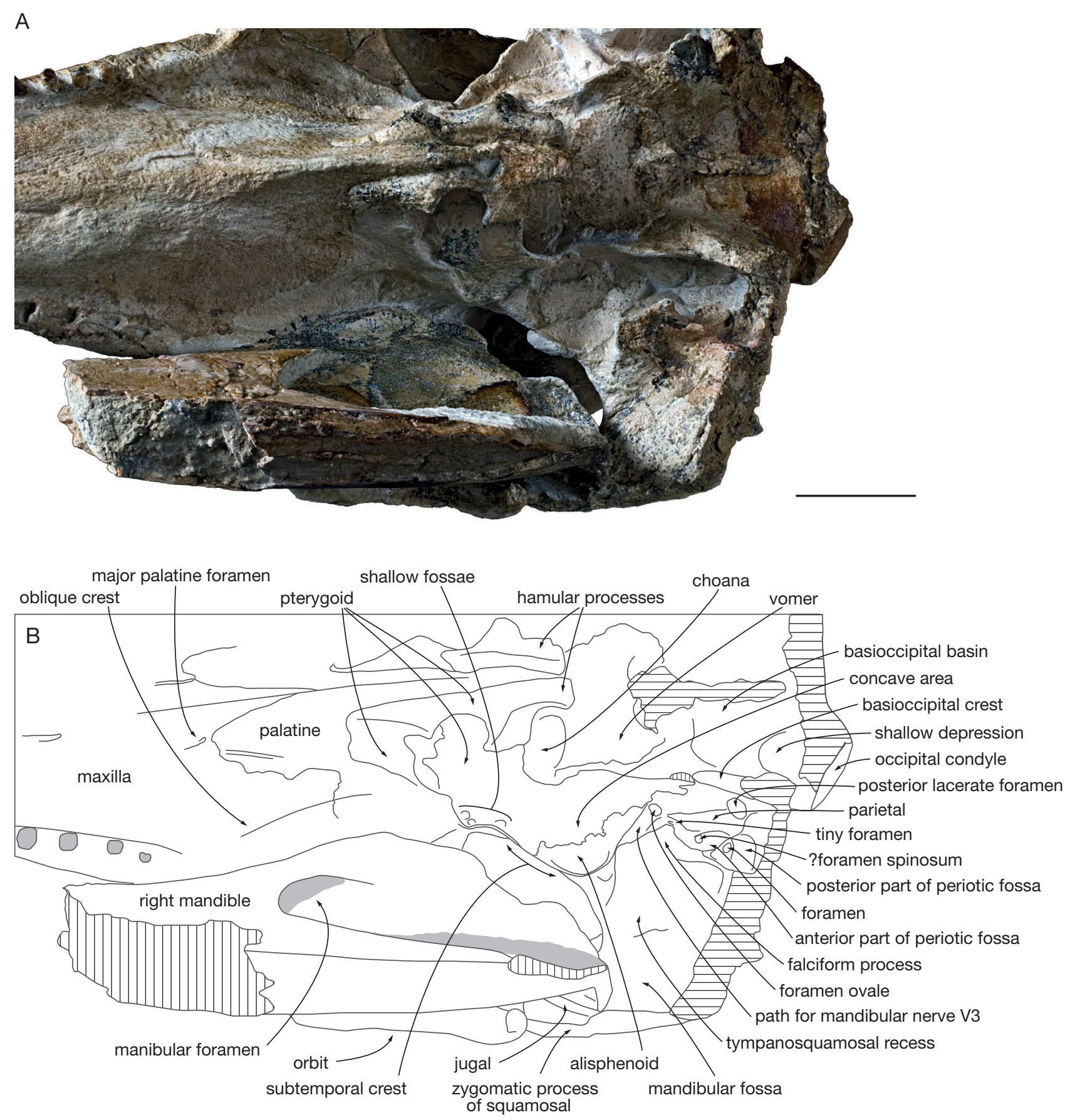

FIG. 7. - Detail of the palate and basicranium of the skull and part of right mandible of Chilcacetus cavirhinus n. gen., n. sp., MNHN.F.PRU11 (holotype), in right ventrolateral view: A, photograph; B, interpretive drawing. Hatching for surfaces of break; shading for sediment. Scale bar: $50 \mathrm{~mm}$.

The floor of the temporal fossa (= squamosal fossa) is longitudinally concave.

The mandibular fossa is wide, anteroventrally and slightly medially facing. Its lateral margin forms a prominent ventrally developed crest, increasing the height of the zygomatic process in lateral view, but not to the extent of platanistids and squalodelphinids. Medially, the mandibular fossa is only poorly separated by a subtle step from the tympanosquamosal recess (Fig. 7). The latter does not extend to the medial face of the zygomatic process beyond the level of the anterior limit of the floor of the temporal fossa. Preserved in the holotype, the falciform process of the squamosal is a wide and long plate, directed anteroventromedially, extending ventrally nearly to the level of the basioccipital crest at the same longitudinal level. On the better-preserved left side, there is no indication of any major break or any sutural contact surface for the lateral lamina of the pterygoid on the anterior margin of the falciform process. Both the postglenoid process and spiny process were lost on the two sides of both specimens. Based on the interpretation of the 
A
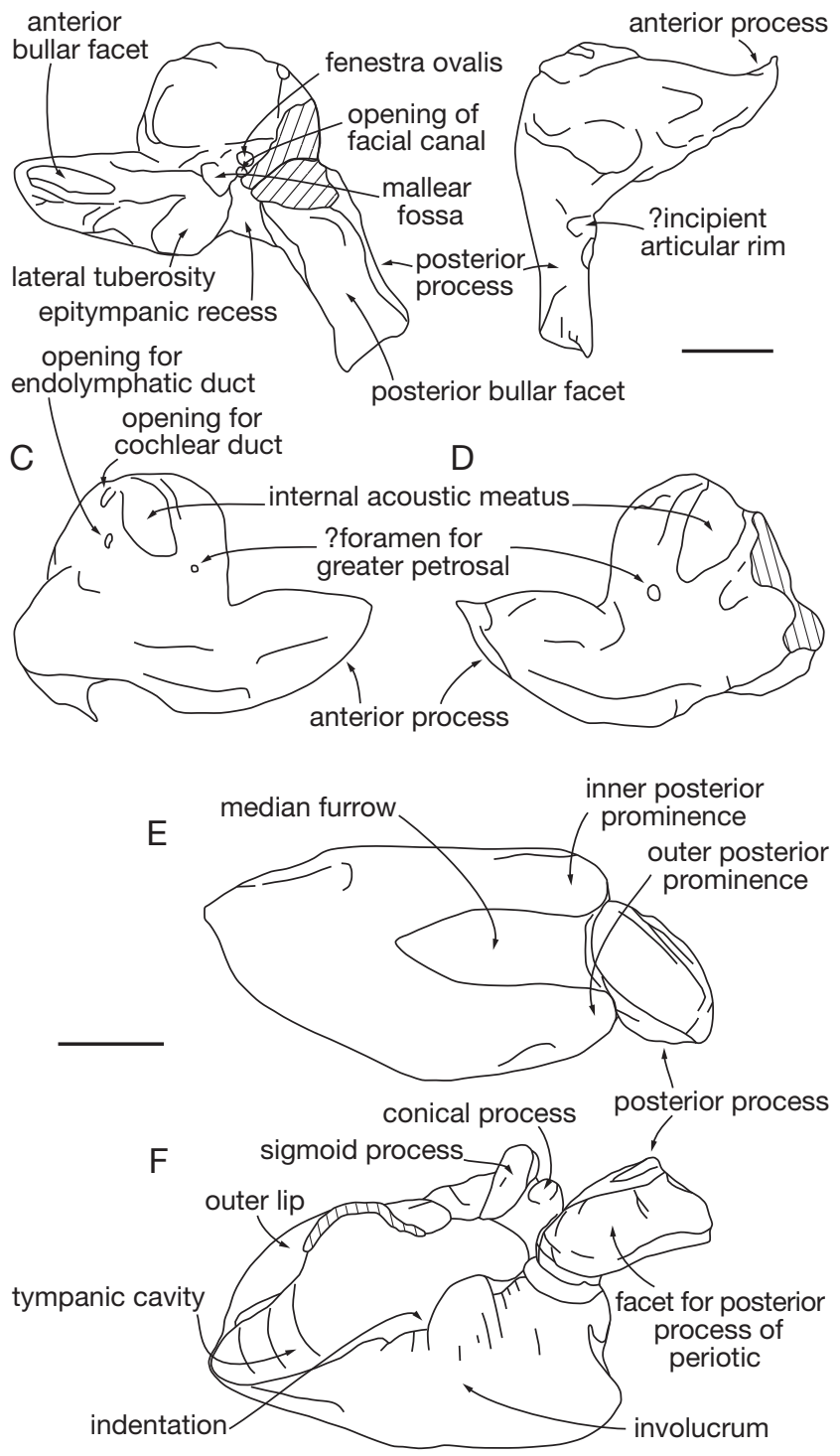

FIG. 8. - Interpretive drawings of the ear bones of Chilcacetus cavirhinus n. gen. n. sp., MNHN.F.PRU11 (holotype), based on preliminary drawings: A-C, right periotic in ventral (A), dorsolateral (B), and anterodorsal and slightly medial (C) views; D, left periotic in anterodorsal and slightly medial view; E, F, right tympanic bulla in ventral $(\mathbf{E})$ and mediodorsal $(\mathbf{F})$ views. Hatching for surfaces of break. Scale bars: $10 \mathrm{~mm}$.

morphology of the basicranium in Waipatia (Fordyce 1994) we identify in the holotype an anteroposteriorly long $(24 \mathrm{~mm}$ on the right side) periotic fossa in the medial portion of the squamosal. The fossa is divided in two by an elevated oblique ridge (?supratubercular ridge sensu Fordyce 1994), which corresponds to the posteromedial continuation of the falciform process. The posterior portion of the periotic fossa, deeper and more clearly defined with a longitudinal diameter of $17 \mathrm{~mm}$, contains a foramen along the oblique ridge. This fossa seems homologous to the subcircular fossa described by Muizon (1987) in Notocetus Moreno, 1892. The shallower anterior portion of the fossa, only distinct on the right side, is pierced by one or two foramina, one of them likely corresponding to the foramen spinosum noted by Fordyce (1994) in Waipatia. Anterior to the fossa, at mid-length between the presumed foramen spinosum and foramen ovale, is a tiny foramen in a position similar to foramen 1 in Waipatia.

Exoccipital. The occipital condyles are prominent, with a distinct condylar neck. The dorsal condyloid fossa is moderately deep, possibly somewhat exaggerated by the dorsoventral crushing of the cerebral cavity in both specimens (Figs 5D;11F). The paroccipital process is lost on both sides of the holotype, as well as the ventral part of the long lateral portion of the bone. In MUSM 1401, the exoccipital is projected laterally, with an acute dorsolateral angle towards the sternomastoideus fossa.

Basioccipital. The basioccipital crests of the holotype are heavily worn ventrally. The basioccipital basin is wide anteriorly; posteriorly the crests diverge moderately to form an angle of about $40^{\circ}$ (Fig. 5C). On the posterolateral region of the basin, along the base of the crest, a shallow depression is limited anteromedially by a low but distinct crest turning anterolaterally, probably corresponding to the insertion of the cervical vertebrae muscle rectus capitis ventralis (see Evans \& Lahunta 2013).

\section{Ear bones}

Based on preliminary drawings and observations (see comments above), several features of the now lost periotics and tympanic bulla of the holotype can be provided.

Periotic. The total length of the right periotic is $41 \mathrm{~mm}$. On the moderately long and pointed anterior process, the anterior bullar facet is a long, well-excavated fossa (Fig. 8A) reminiscent of the condition in eurhinodelphinids, platanistids, squalodelphinids, and ziphiids, deeper though than in Papahu, Simocetus, allodelphinids, and squalodontids. In dorsomedial view, the anterior process is somewhat transversely swollen towards its base, with a ventromedial margin more convex than in most eurhinodelphinids. The pars cochlearis is large with a nearly rectilinear anterior margin and a slightly convex medial margin in ventral view. The lateral tuberosity is elongated anterolateral to the mallear fossa, more so than in eurhinodelphinids; a long lateral tuberosity is observed in many ziphiids, but it is directed more laterally than anterolaterally. The long posterior process appears roughly rectilinear, projecting posterolateroventrally. This process is distinctly longer than in all known eoplatanistids, eurhinodelphinids, platanistids, ziphiids, and even squalodelphinids, and it is directed more laterally, more similar to the condition in the xenorophiid Albertocetus (see Uhen 2008) and probably Simocetus (obscured in the latter by the posterior process of the tympanic; Fordyce 2002). On the dorsolateral margin of the bone, posterior to the epitympanic recess, is a low tubercle (Fig. 9B) that might correspond to the incipient articular rim of Waipatia (Fordyce 1994) and eurhinodelphinids. The articular rim/ process is more developed in platanistids, squalodelphinids, 
and at least some squalodontids, than in eurhinodelphinids and Waipatia, with a deeper and wider groove between this element and the lateral margin of the posterior bullar facet (see Muizon 1987); it is generally lower or absent in ziphiids, and possibly absent in eoplatanistids. The internal acoustic meatus is roughly oval but only slightly pointed anterolaterally (Fig. 8C, D). In both the left and right periotics, a small opening is noted anterolateral to the tip of the meatus; it is interpreted as homologous to the ?foramen for greater petrosal observed in Eurhinodelphis cocheteuxi and Waipatia (Fordyce 1994; Lambert 2005; hiatus Fallopii sensu Mead \& Fordyce 2009). Along the posterolateral margin of the meatus is a small aperture for the endolymphatic duct; the aperture for the cochlear duct was possibly larger than the latter, close to the posteromedial margin of the hiatus.

Tympanic bulla. The length of the left tympanic, without the posterior process, is $39 \mathrm{~mm}$. In ventral view, it is oliveshape (Fig. 8E), with a pointed anterior margin lacking a defined anterior spine (considering the dorsoventrally flattened anterior margin) and without the deep anterolateral notch seen in pomatodelphinines and squalodelphinids (see Muizon 1987). Inner and outer posterior prominences have the same posterior extent, differing from platanistids. The inner prominence is slightly narrower than the outer prominence, a difference not as marked as in several, but not all, eurhinodelphinids and ziphiids (Lambert 2004, 2005a, b; Bianucci et al. 2010). The median furrow is deep and extends anteriorly farther than the mid-length of the bone, roughly similar to Macrodelphinus, eurhinodelphinids, squalodontids, and ziphiids. The median furrow is anteriorly longer in platanistids and squalodelphinids, whereas it is roughly absent in eoplatanistids (Muizon 1988b). The dorsal margin of the involucrum is cut by a vertical indentation at mid-length (Fig. 8F), as in eoplatanistids and eurhinodelphinids. In ziphiids, the indentation is usually mostly seen in dorsal view, whereas it is visible in both dorsal and medial views in eoplatanistids and eurhinodelphinids. Interestingly, even if lower, a similar indentation is also observed in Albertocetus, whereas no clear indentation is present in Waipatia, platanistids, squalodelphinids, and squalodontids. In dorsomedial view, the sigmoid process is directed anteromedially.

\section{Teeth}

21 teeth of the holotype are preserved in situ in the maxillae; among them, only nine are complete to subcomplete. All the teeth, from the anterior to the posterior-most are simple, conical, and single-rooted (Figs 4; 5A, B; 9), contrasting with Squalodon and Waipatia. The teeth from the anterior third of the preserved length of the alveolar groove are the highest, with the height outside the alveolus reaching $13.4 \mathrm{~mm}$. They are slightly less robust, with transverse and anteroposterior diameters respectively ranging from 6 to 6.4 and from 5.6 to $6.8 \mathrm{~mm}$. The teeth from the second third are lower, with the height outside the alveolus reaching $11.8 \mathrm{~mm}$ in the last teeth. The transverse and anteroposterior diameters are
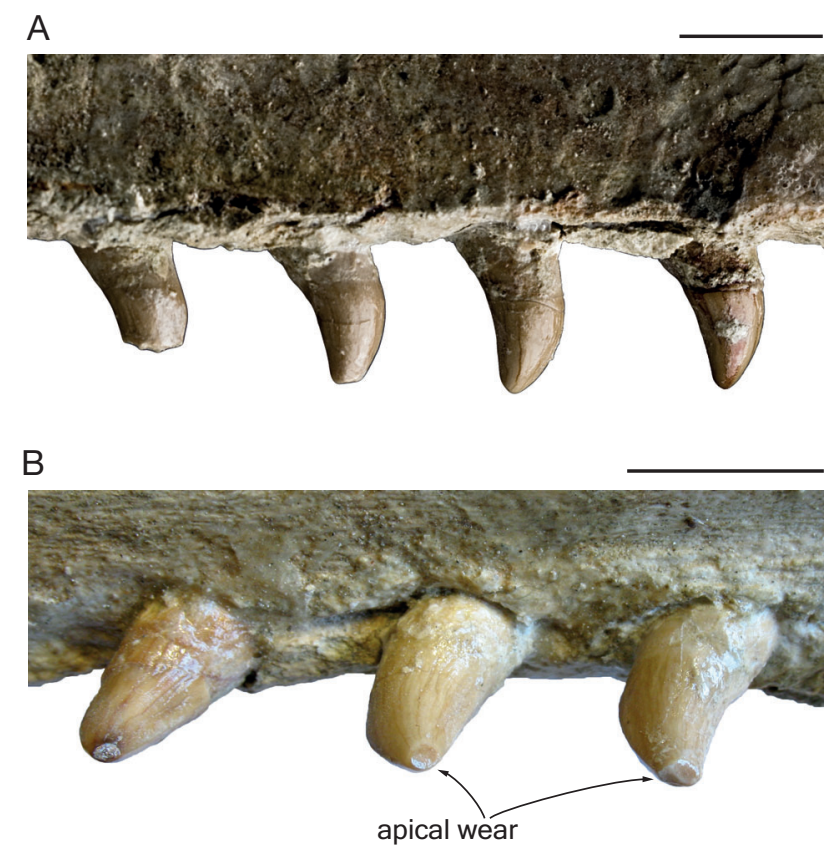

FIG. 9. - Right posterior maxillary teeth of Chilcacetus cavirhinus n. gen., n. sp., MNHN.F.PRU11 (holotype): A, lateral view; B, ventromedial view. Scale bars: $10 \mathrm{~mm}$.

generally larger, up to 7.2 and $7.1 \mathrm{~mm}$ respectively. In the posterior third, these diameters decrease to 5.5 and $5.7 \mathrm{~mm}$ respectively in the last preserved teeth (on the left alveolar row of the holotype, only the last posterior tooth is lost). Posterior teeth are also somewhat more ventromedially curved. Low mesial and distal keels are observed in all the preserved teeth; these subtle keels are neither crenulated nor do they bear accessory denticles. The enamel is nearly smooth (Fig. 9), only marked by longitudinal grooves lighter than in Macrodelphinus. Exposed roots of anterior teeth are not inflated, but they do display a distinctly posteriorly projecting apex.

\section{Tooth wear}

Two anterior teeth display an intact apex whereas a nearly vertical wear surface is present on the apex of two more curved posterior teeth (Fig. 9B). This wear surface might correspond to an occlusion facet, instead of a tooth-to-food item contact. As in Macrodelphinus, the crown base is marked by a shallow occlusion facet on the distal surface of several teeth within the second third of the tooth row, corroborating the hypothesis for the presence of embrasure pits posterior to some maxillary teeth.

\section{Mandible}

An in situ $488 \mathrm{~mm}$ long portion of the right mandible of the holotype includes a part of the long symphysis, as well as most of the post-symphyseal region $(355 \mathrm{~mm})$. The latter is somewhat dorsoventrally crushed and lacks the angular process (Figs 4; 7). The main mandibular fragment from MUSM 1401 (Fig. 12A, B) is a portion of the right dentary that includes at least $267 \mathrm{~mm}$ of the symphyseal region. The symphyseal surface, marked by longitudinal grooves and ridges without 
A
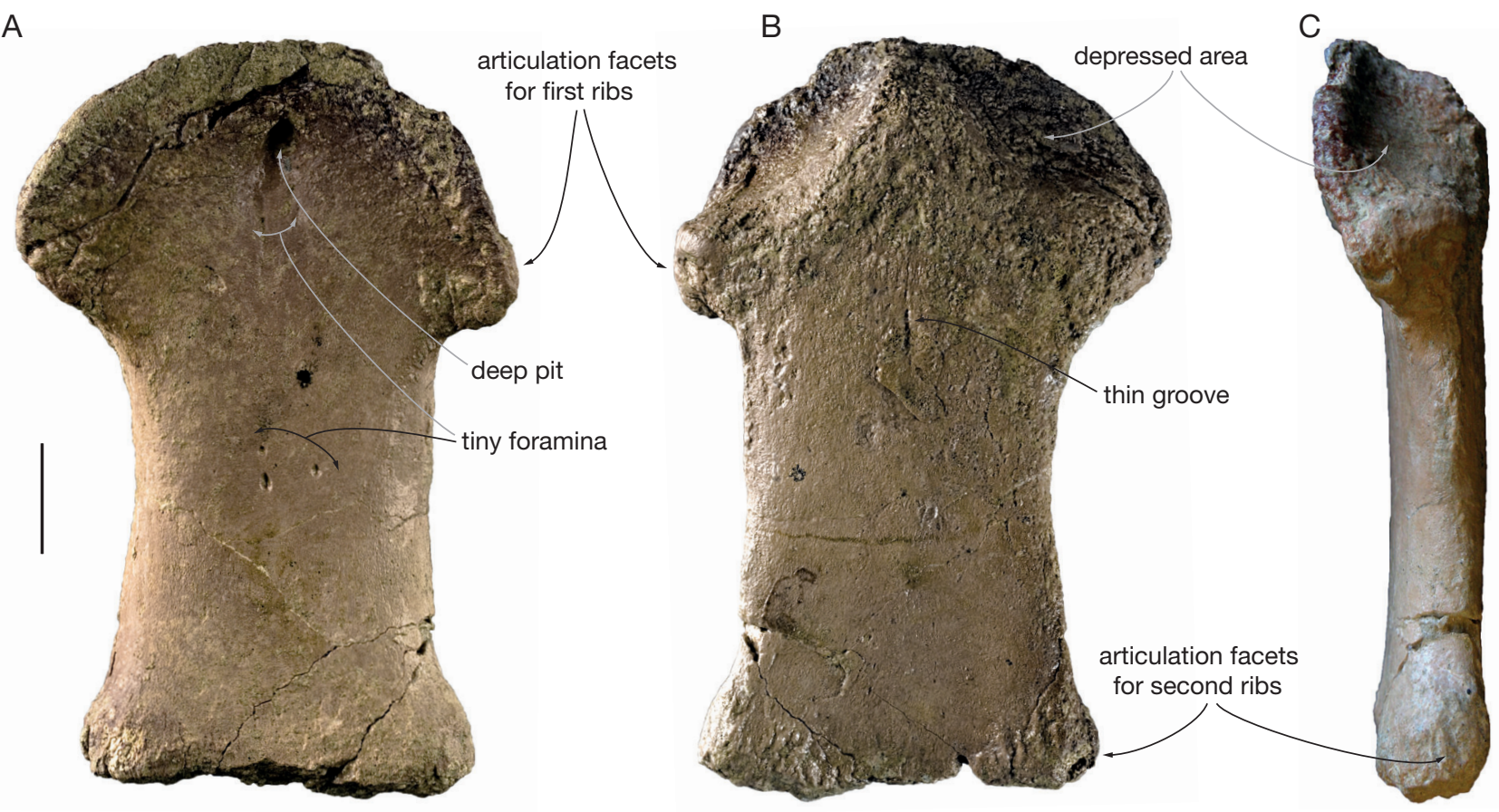

FIG. 10. - Manubrium (presternum) of Chilcacetus cavirhinus n. gen., n. sp., MNHN.F.PRU11 (holotype), in dorsal (A), ventral (B), and right lateral (C) views. Scale bar: $20 \mathrm{~mm}$.

indication of major break, indicates that dentaries were not ankylosed in both the holotype and MUSM 1401, differing from the condition of allodelphinids, eoplatanistids, eurhinodelphinids, platanistids, squalodelphinids, and Argyrocetus patagonicus, but similar to Macrodelphinus. The height and width of the section of the dentary at the posterior end of the symphysis are 34 and $26 \mathrm{~mm}$ respectively in the holotype; taken together, the two dentaries were wider than high at that level moving forwards. Where preserved, the ventral margin of the mandible is roughly rectilinear. The dorsal margin raises gently towards the coronoid process, less abruptly than in Papahu. A slightly convex portion of this margin, posterior to the last alveolus, is not as developed as the precoronoid crest observed in ziphiids and some delphinoids (Fordyce et al. 2002; Lambert et al. 2013). The maximum height of the coronoid process above the mandibular condyle of the holotype is approximately $35 \mathrm{~mm}$, proportionally lower than the posterodorsally elevated process in Albertocetus and, in a lesser extent, Waipatia. The condyle is $51 \mathrm{~mm}$ high, with a ventral margin distinct from the ventral-most margin of the ramus, differing on this point from physeteroids (Bianucci \& Landini 2006).

On the lateral surface of the mandible of the holotype, at least eight small mental foramina are counted, in an oblique line from the coronoid region to the anteroventral margin. As in Macrodelphinus, no lateral groove is detected in either of the two specimens, differing from eoplatanistids, eurhinodelphinids, and platanistids.

The preserved part of the symphyseal region of the holotype contains more than 10 alveoli, whereas 10 simple alveoli were counted on the post-symphyseal region. Their transverse diameters range from 6.1 to $6.9 \mathrm{~mm}$, and interalveolar septa are 6 to $8.5 \mathrm{~mm}$ thick. In MUSM 1401, 22 alveoli are counted on $296 \mathrm{~mm}$, with transverse diameters of 8-11 $\mathrm{mm}$. The rounded anterior margin of the dorsoventrally high mandibular foramen of the holotype reaches a level $125 \mathrm{~mm}$ from the posterior surface of the mandibular condyle (Fig. 7). With the mandible virtually repositioned in articulation with the skull, this anterior limit roughly corresponds to the anterior end of the pterygoid sinus fossa on the palate.

\section{Manubrium (presternum)}

This first segment of the sternum of the holotype, not frequently described in fossil odontocetes, is free from the second segment and roughly complete (Fig. 10). The maximum length is $132 \mathrm{~mm}$, the maximum width at the level of the articulation surface with the first rib is $88 \mathrm{~mm}$, the maximum posterior width is $71 \mathrm{~mm}$, the minimum width of the body is $53 \mathrm{~mm}$, and the maximum dorsoventral thickness at mid-length is $18 \mathrm{~mm}$. This is larger but thinner than in the pomatodelphinine Zarhachis Cope, 1868 (see Kellogg 1924). The general outline and proportions of the manubrium, are more similar to the ancient physeteroid Ferecetotherium Mchedlidze, 1970 (see Mchedlidze 1976) and the stem-ziphiid Ninoziphius (see Muizon 1984), proportionally narrower anteriorly than in the extant sperm whale Physeter Linnaeus, 1758, and less stocky than in extant ziphiids, with a more abrupt widening towards the articulation surface with the first rib than in the latter. This articular surface is positioned more posteriorly on the manubrium as compared to the 

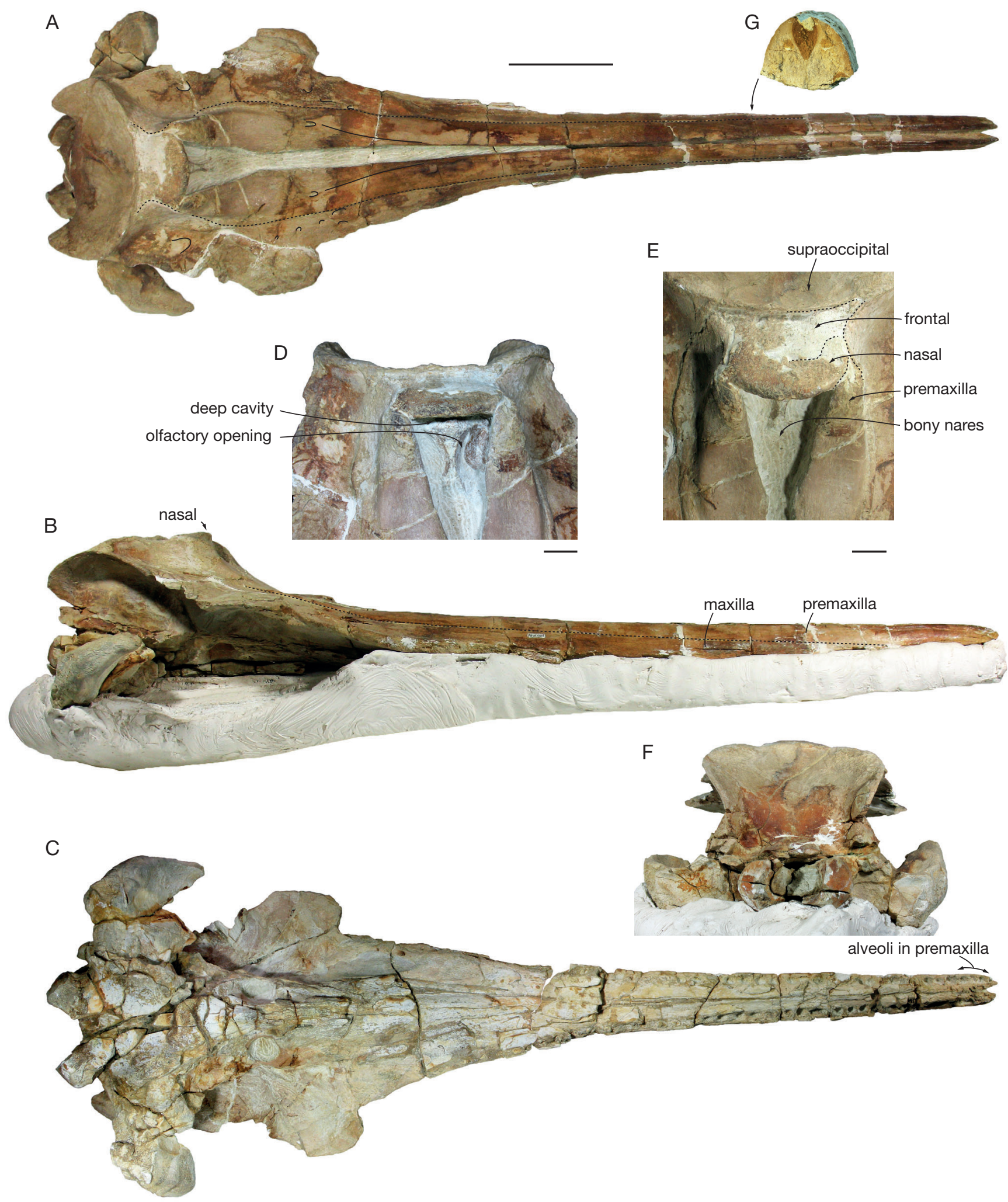

FIG. 11. - Skull of Chilcacetus cavirhinus n. gen., n. sp., MUSM 1401, in dorsal (A), right lateral (B), ventral (C), and posterior (F) views; D, E, detail of the vertex in anterodorsal and slightly lateral (D) and dorsal (E) views; G, transverse section in the rostrum at one third of its length. Scale bars: A-C, F, $100 \mathrm{~mm}$; D, E, $20 \mathrm{~mm}$. G, enlarged $2 x$ compared to $A$.

same articular surface in Dorudon Gibbes, 1985 (see Uhen 2004), Kogia Gray, 1846 (see Schulte \& Smith 1918), Platanista Wagler, 1830, Physeter, and Sulakocetus Mchedlidze,
1976, a possible waipatiid (Fordyce, 1994). Differing from Ninoziphius, most other ziphiids, and several other odontocetes (including kentriodontids, Inia, Pontoporia 
TABLE 2. - Hypothetical position in the vertebral column and measurements (in millimeters) for eight partial vertebrae of Chilcacetus cavirhinus n. gen., n. sp. MUSM 1401. Abbreviations: e, estimate; +, incomplete; -, missing data.

\begin{tabular}{llccc}
\hline Position & $\begin{array}{c}\text { Centrum } \\
\text { length }\end{array}$ & $\begin{array}{c}\text { Centrum } \\
\text { height }\end{array}$ & $\begin{array}{c}\text { Width of } \\
\text { epiphysis }\end{array}$ \\
\hline 1 & ?cervical & +28 & 47 & - \\
2 & cervical or thoracic & +32 & 45 & e50 \\
3 & thoracic & +34 & 43.5 & 47.5 \\
4 & $?$ & +33 & - & \\
5 & thoracic or lumbar & 42 & - & +60 \\
6 & thoracic or lumbar & 54 & - & +53 \\
7 & thoracic or lumbar & 56 & - & - \\
8 & thoracic or lumbar & +70 & - & - \\
\hline
\end{tabular}

Gray, 1846, monodontids and several delphinids, see for example Muizon 1988a: fig. 107), the anterior margin is not cut by a distinct notch and was likely originally smoothly convex transversely. The posterior margin was originally rectilinear. The posterolateral corners are thick, corresponding to the areas of articulation of the second pair of ribs. The ventral surface is concave between these thicker regions. A barely visible ridge marks the sagittal plane on part of the posterior half of the ventral surface, whereas a thin and short groove is observed more anteriorly, up to the level of the articular surface for the first rib. From that level onwards, a strong sagittal crest divides the ventral surface into two depressed areas that face anteroventrolaterally. A slight crest is observed in the same region in some mysticetes, for example Balaenoptera musculus and Caperea; a wide and deeply concave anterolateral area is also described by Wilson (1935; not figured) in Macrodelphinus, but with a $23 \mathrm{~mm}$ long anterior projection lacking in the holotype of Chilcacetus cavirhinus n. gen., n. sp. In lateral view, the anterolateral margin of each depression curves anteroventrally, as seen in several delphinids. This anterior region is moderately asymmetric, with the left side more anterolaterally developed than the right side. The depressed areas probably correspond to the regions of origin of the sternohyoid muscle, inserting on the basihyal and thyrohyal in extant odontocetes; contractions of this muscle are thought to pull posteroventrally the hyoid apparatus, as well as the tongue and floor of the mouth (Reidenberg \& Laitman 1994). The moderate asymmetry observed in the holotype of Chilcacetus cavirhinus n. gen., n. sp. might be related to the laryngeal asymmetry generally observed in odontocetes, allowing them to swallow larger prey around the larynx (Reidenberg \& Laitman 1994; McLeod et al. 2007). On the dorsal surface, three tiny foramina are observed in the middle of the body. A few more tiny foramina are located posterior to a deep and narrow pit just before the anterior margin of the manubrium. This depression, not completely piercing the bone, might be a remnant either of a larger foramen, present in the same area in several delphinids (e.g., Globicephala melas Traill, 1809 and Lagenorhynchus acutus [Gray, 1828]), or of a deep notch as seen in several ziphiids.

\section{Vertebrae}

Eight vertebrae of MUSM 1401 are partly preserved; the transverse apophyses are usually broken at the base and even the centra are incomplete. Based on the few elements at hand, it is difficult to identify their position, even approximate, along the vertebral column. Three of these vertebrae are illustrated in Figure 12C-F and a few measurements are provided in Table 2. When the epiphyses are preserved, they are ankylosed to the corresponding centrum, suggesting that the animal was adult.

\section{Ribs}

Only a few fragments of ribs of MUSM 1401 are preserved. Two of them are illustrated in Figure 12G-H. Two shark tooth marks, simple and roughly rectilinear, are observed on one of the rib fragment. Such tooth marks are commonly observed in the field on bony remains of small odontocetes from the Chilcatay Formation.

\section{INTRASPECIFIC VARIATION}

As detailed above, the holotype of Chilcacetus cavirhinus n. gen., n. sp. differs from the referred specimen MUSM 1401 in several morphological features: a more extended contact between the premaxillae above the mesorostral groove; a wider and longer posterior apex of the premaxilla along the nasal, widely contacting the frontal on the vertex; a greater exposure of the frontals on the vertex; and longitudinally longer, transversely thicker, and less posteriorly projected temporal crests, limiting a proportionally wider supraoccipital shield (Table 1). Because these two specimens originate from the same lithological unit and from geographically close localities, and based on the observation of the variation of the cranial morphology within extinct and extant odontocete species (e.g., Perrin 1975), we propose that these differences between the two otherwise very similar skulls correspond to intraspecific variation. Additional specimens from the Chilcatay Formation are needed to confirm or refute this hypothesis.

\section{PHYLOGENY}

\section{ANALYSIS AND RESULTS}

The phylogenetic relationships of Chilcacetus cavirhinus n. gen., n. sp. were investigated. The sample analyzed includes other homodont long-snouted odontocetes (Allodelphinidae, Argyrocetus patagonicus, 'Argyrocetus' bakersfieldensis, 'Argyrocetus' joaquinensis, Macrodelphinus, Eoplatanista, Eurhinodelphinidae, and Platanistidae), Squalodelphinidae, Squalodon, Waipatia, Ziphiidae, a few delphinidans (Kentriodon Kellogg, 1927, Pontoporia, and Delphinus Linnaeus, 1758), and the basilosaurid Zygorhiza True, 1908 as outgroup. We did not have the opportunity to observe the original or a cast of the holotype of Papahu taitapu Aguirre-Fernández \& Fordyce, 2014, so this other archaic homodont odontocete is for now only commented above in the diagnosis and the description. 
A

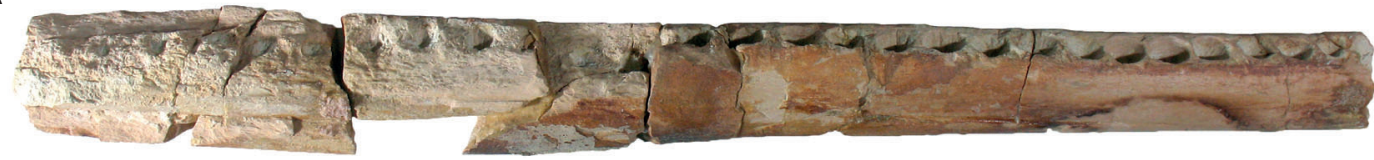

B
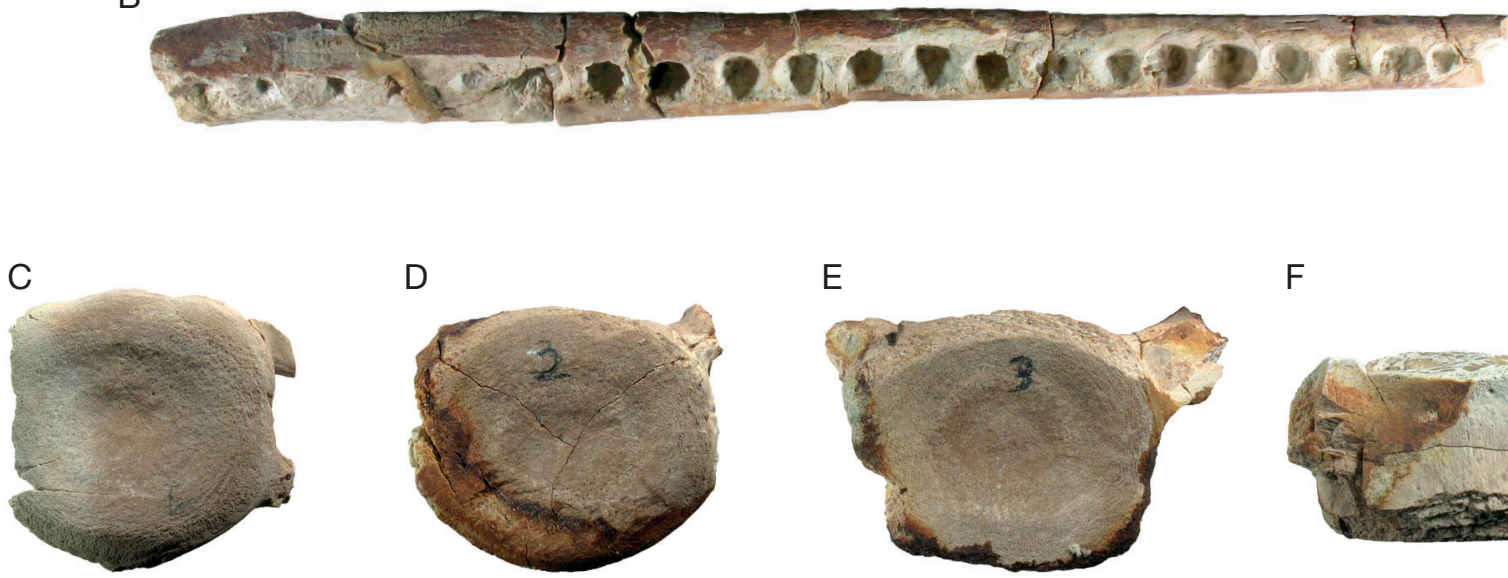

D

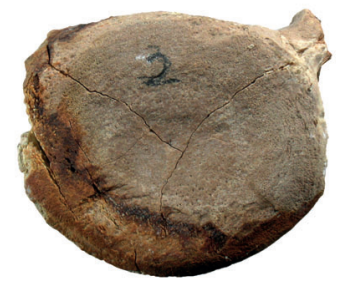

E

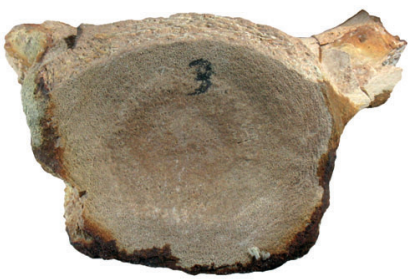

F

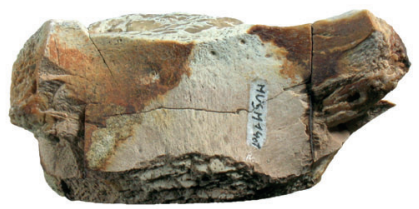

G

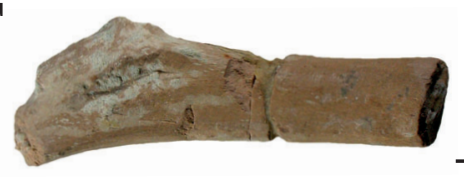

$\mathrm{H}$

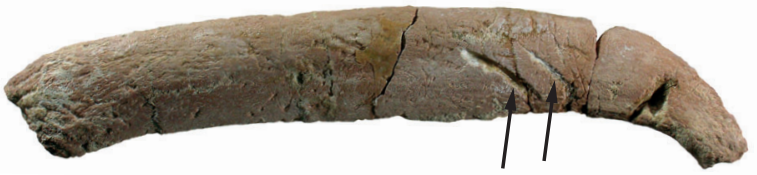

FIG. 12. - Mandible and postcranial remains of Chilcacetus cavirhinus n. gen., n. sp., MUSM 1401: A, B, fragment of right dentary in lateral (A) and dorsal (B) views; C-F, vertebrae (corresponding to vertebrae 1-3 in Table 2); C, ?cervical in anterior or posterior views; $\mathbf{D}$, cervical or thoracic in anterior or posterior views; $\mathbf{E}, \mathbf{F}$, thoracic in anterior or posterior views (E) and dorsal view (F); $\mathbf{G}, \mathbf{H}$, rib fragments. Note the shark tooth marks in $\mathbf{H}$ (arrows). Scale bars: A, B, 50 mm; C-F, $\mathrm{G}, \mathrm{H}, 20 \mathrm{~mm}$.

Character states were designed to be plesiomorphic (0) or derived (1-n) according to the outgroup comparison method of Maddison et al. (1984). The matrix includes 77 morphological characters; 52 binary $(1,3,5,7,8,9,10,12,13,14$ $15,16,17,18,22,23,26,30,31,36,37,39,40,41,42,44$, $48,50,51,52,53,54,55,57,58,59,60,61,63,64,65,66$, $67,68,69,71,72,73,74,75,76,77)$ and 25 multistate and unordered $(2,4,6,11,19,20,21,24,25,27,28,29,32$, $33,34,35,38,43,45,46,47,49,56,62,70$ ) (see Appendix 2 for the list of characters and Appendix 3 for the character/ taxon matrix). Most, but not all, of the 77 characters are recombined from two recently published phylogenetic analyses (Lambert et al. 2013, 2014). Considering all characters as non-additive (unordered), the analysis was conducted using PAUP (version 4.0b10; Swofford 2001), applying the heuristic search option with simple taxon addition and 'maxtree' set to 10000 , optimized by ACCTRAN using the tree bisection and reconnection (TBR) algorithm. Bootstrap analyses were carried out with 1000 replications. As preliminary analyses led to poorly resolved trees, we down-weighted the homoplastic characters using the default value of 3 for the constant $k$ of the method following Goloboff (1993). The cladistic analysis produced three equally parsimonious trees, with tree length
228, Goloboff fit -60.65 , Consistency Index (CI) 0.47, and Retention Index (RI) 0.75 . The consensus tree of these cladograms and the associated bootstrap support values are presented in Figure 13 and are discussed below.

\section{DISCUSSION}

The consensus tree (Fig. 13) suggests that Chilcacetus cavirhinus n. gen., n. sp. belongs to a clade (here named "Chilcacetus clade") also including Argyrocetus patagonicus, 'Argyrocetus' bakersfieldensis, 'Argyrocetus' joaquinensis, and Macrodelphinus. A single derived character is shared by all these taxa: the dorsal surface of the nasal rising anterodorsally (char. 30, state 1). However, among other odontocetes considered in this analysis, this character is also observed in some specimens of Eoplatanista and in the eurhinodelphinid Ziphiodelphis abeli. Chilcacetus n. gen. shares with most of the taxa of the Chilcacetus $\mathrm{n}$. gen. clade the plesiomorphic state for the following characters: extended edentulous anterior premaxillary portion of the rostrum (char. 2, derived state 2 in Eurhinodelphinidae and part of Ziphiidae); lateral rostral suture between premaxilla and maxilla deeply grooved (char. 3, derived state in Allodelphinidae, Eoplatanista, Eurhinodelphinidae, and Platanistidae); elevated antorbital region distinctly higher than 
the dorsal margin of the rostrum base in lateral view (char. 12, derived state in Eoplatanista, most of Eurhinodelphinidae, Platanistidae, Pontoporia, Squalodelphinidae, and Zarhinocetus Barnes \& Reynolds, 2009); cranium distinctly shorter than wide (char. 15, derived state in Allodelphinidae, Eurhinodelphinidae, Platanistidae, Squalodelphinidae, Squaloziphius, and Ziphiidae); transverse widening of the supraoccipital (char. 34, derived state 2 in Allodelphinidae, Delphinida, Eurhinodelphinidae, Squaloziphius, and Ziphiidae); anteroposterior shortening of the zygomatic process of the squamosal (char. 42, derived state in Allodelphinidae Eurhinodelphinidae, and Ziphiidae); dorsal margin of the temporal fossa considerably lower than the top of the nuchal crest (char. 46, derived states 2-3 in Allodelphinidae, Argyrocetus patagonicus, Delphinida, Eurhinodelphinidae, Platanistidae excluding Platanista, Squalodelphinidae, Squaloziphius, and Ziphiidae); and nearly complete fusion of the symphysis on the mandibles (char. 72, derived state in Allodelphinidae, Argyrocetus patagonicus, some Delphinida, Eoplatanista, Eurhinodelphinidae, Platanistidae, Squalodelphinidae, and most of the Ziphiidae).

This list of plesiomorphic states supports the hypothesis that Chilcacetus n. gen. and other members of its clade are not early branching eurhinodelphinids. Within the Chilcacetus n. gen. clade, 'Argyrocetus' joaquinensis is the first taxon to diverge. The four other taxa share an acute anterior margin of the nasal partly overhanging the bony nares (char. 31, state 1). Chilcacetus n. gen. appears more closely related to 'Argyrocetus' bakersfieldensis in having wider premaxillae at the rostrum base (char. 8 , state 1 ). With the limited number of characters available, the three-species genus Argyrocetus appears paraphyletic.

The Chilcacetus n. gen. clade branches before a large clade made of all other homodont odontocetes included in this analysis. Crownward to the Chilcacetus n. gen. clade, successive branches correspond to Eoplatanista, Eurhinodelphinidae, homodont Platanistoidea (Allodelphinidae + Platanistidae + Squalodelphinidae), Delphinida, Squaloziphius, and Ziphiidae. A sister-group relationship between Delphinida and Ziphiidae, with Platanistidae more distantly related, is found in some, but not all, molecular and supermatrix studies (e.g., Hamilton et al. 2001; McGowen et al. 2009; Steeman et al. 2009; Gatesy et al. 2013). The heterodont Squalodon and Waipatia were often considered as belonging to the superfamily Platanistoidea (e.g., Muizon 1991; Fordyce 1994); they are here separated from homodont members of the superfamily, a result found in other recent analyses (e.g., Geisler et al. 2011,2012 ), but that needs to be further tested with a larger number of characters and taxa.

The bootstrap analysis indicates that the relationships of Chilcacetus n. gen. with other taxa of the Chilcacetus n. gen. clade, the relationships within Eurhinodelphinidae, as well as the position of Eoplatanista and Squaloziphius, are weakly supported (bootstrap < 50); further work, including a redescription of known specimens and the description of new material (for several of the taxa mentioned here, ear bones are for example unknown), is needed to get better resolution. For now, we refrain from officially naming the

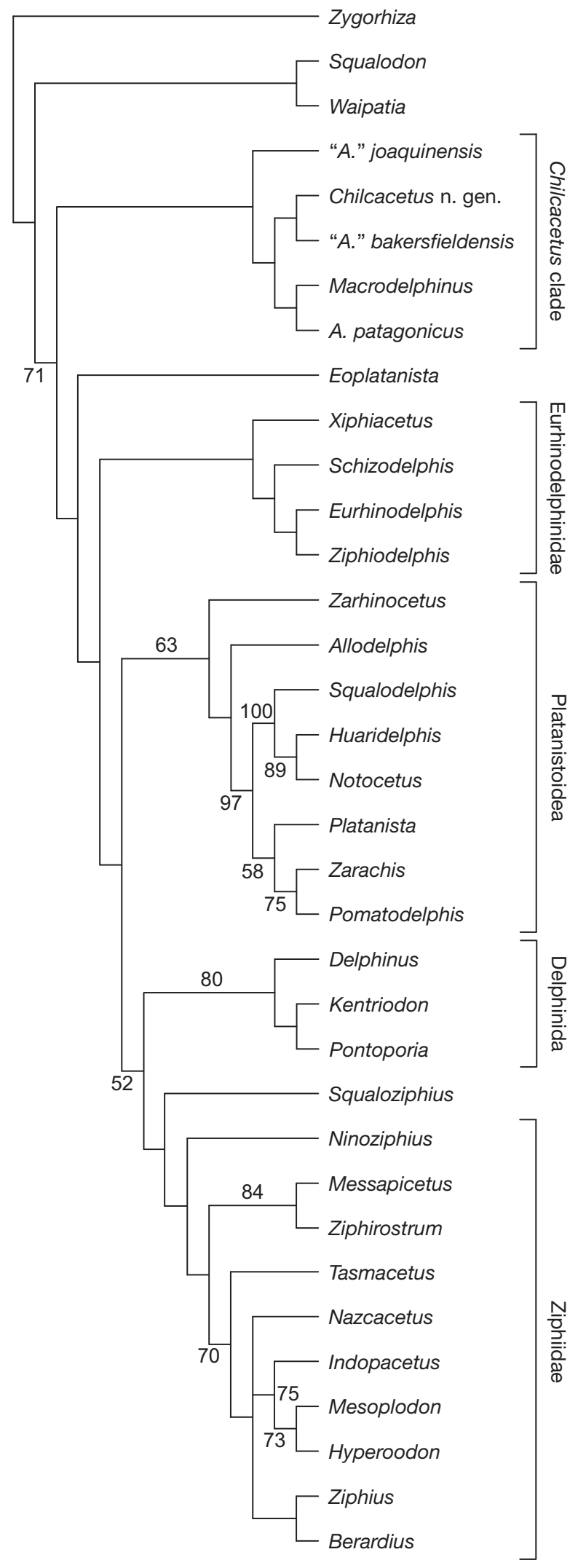

FIG. 13. - Consensus of three equally parsimonious trees resulting from the cladistic analysis (downweighting homoplastic characters) of 34 odontocete taxa, showing the relationships of Chilcacetus cavirhinus n. gen., n. sp. with other homodont toothed whales. Numbers at nodes correspond to associated bootstrap values. The Chilcacetus clade is not officially named due to poor support. 
Chilcacetus $\mathrm{n}$. gen. clade, considering the low support and the lack of unambiguous synapomorphies. Nevertheless, it is interesting to note that, apart from Argyrocetus patagonicus, all the members of the Chilcacetus n. gen. clade have a Pacific Ocean distribution, suggesting that this clade of archaic homodont dolphins had a moderately restricted distribution, in the Northeast Pacific ('Argyrocetus' bakersfieldensis, 'A.' joaquinensis, and Macrodelphinus kelloggi) and on both coasts of South America (A. patagonicus and C. cavirhinus).

\section{Acknowledgements}

We wish to thank W. Aguirre, E. Díaz, R. Salas-Gismondi, J. Tejada, M. Urbina, and R. Varas for their help during fieldwork and for the preparation of MUSM 1401, T. DeVries and M. Urbina for useful comments about the localities of the Chilcatay Formation and its stratigraphy, P. Agnelli, L. G. Barnes, D. Berthet, D. J. Bohaska, L. Del Favero, M. Fornasiero, U. Franzrahe, Z. N. Gasparini, C. Lefevre, G. Lenglet, J. G. Mead, C. Nocchi, J. J. Ososki, M. A. Reguero, L. H. Pomi, C. W. Potter, N. D. Pyenson, R. Salas-Gismondi, S. van der Mije, and M. Urbina for providing access to specimens under their care, L. G. Barnes for discussion about different aspects of this work, R. E. Fordyce for providing a ventral view of the holotype of 'Argyrocetus' joaquinensis, and C. Lemzaouda and W. Miseur for the photographic work. We also thank S. J. Godfrey, an anonymous reviewer, and the editor E. Côtez for their constructive comments. The work of OL at the IRSNB during an early phase of this study (2012 to April 2013) was funded by a Return Grant of the Belgian Federal Science Policy Office. This research was also partly supported by a grant of the Italian Ministero dell'Istruzione, dell'Università e della Ricerca (MIUR; PRIN 2012YJSBMK, resp. GB).

\section{REFERENCES}

Aguirre-Fernández G. \& Fordyce R. E. 2014. — Papahu taitapu, gen. et sp. nov., an early Miocene stem odontocete (Cetacea) from New Zealand. Journal of Vertebrate Paleontology 34: 195-210.

AlVÁn DE LA CRUZ A. 2008. - Geología de Ocucaje: aportes en la sedimentología y paleontología de Lomas de Ullujaya (Ica, Perú). Revista del Instituto de Investigaciones FIGMMG 11 (21): 51-59.

BARNES L. G. 1976. - Outline of eastern North Pacific fossil cetacean assemblages. Systematic Zoology 25 (4): 321-343.

BARNES L. G. 2006. - A phylogenetic analysis of the superfamily Platanistoidea (Mammalia, Cetacea, Odontoceti). Beiträge zur Paläontologie 30: 25-42.

BianuCCI G., LAMBert O. \& POST K. 2007. — A high diversity in fossil beaked whales (Odontoceti, Ziphiidae) recovered by trawling from the sea floor off South Africa. Geodiversitas 29 (4): 561-618.

BiANUCCI G., LAMBERT O. \& POST K. 2010. — High concentration of long-snouted beaked whales (genus Messapicetus) from the Miocene of Peru. Palaeontology 53 (5): 1077-1098.

BianUCCI G. \& LANDini W. 2006. - Killer sperm whale: a new basal physeteroid (Mammalia, Cetacea) from the Late Miocene of Italy. Zoological Journal of the Linnean Society 148: 103-131.

BiANUCCI G., URBINA M. \& LAMBERT O. (2015). - A new record of Notocetus vanbenedeni (Squalodelphinidae, Odontoceti, Cetacea) from the early Miocene of Peru. Comptes Rendus Palevol 14 (1): 5-13.
Brisson M.-J. 1762. - Regnum Animale in classes IX distributum, sine synopsis methodica. Theodorum Haak, Paris, 296 p.

Cabrera A. 1926. - Cetaceos fosiles del Museo de La Plata. Revista del Museo de La Plata 29: 363-411.

DE VRIES T. J. 1998. — Oligocene deposition and Cenozoic sequence boundaries in the Pisco Basin (Peru). Journal of South American Earth Sciences 11: 217-231.

DE VRIES T. J. 2001. - Molluscan evidence for an OligoceneMiocene age of 'Paracas' beds in Southern Peru. Boletín de la Sociedad Geológica del Perú 92: 57-65.

Dunbar R. B., Marty R. C. \& Baker P. A. 1990. - Cenozoic marine sedimentation in the Sechura and Pisco basins, Peru. Palaeogeography, Palaeoclimatology, Palaeoecology 77: 235-261.

Evans H. E. \& LAhUnTA A. DE. 2013. - Miller's anatomy of the dog. Fourth edition. Elsevier Saunders, St. Louis, 850 p.

FLOWER W. H. 1867. - Description of the skeleton of Inia geoffrensis and the skull of Pontoporia blainvillii, with remarks on the systematic position of these animals in the Order Cetacea. Transactions of the Zoological Society of London 6: 87-116.

FordYCE R. E. 1994. - Waipatia maerewhenua, new genus and new species (Waipatiidae, new family), an archaic late Oligocene dolphin from New Zealand, in BERTA A. \& Deméré T. A. (eds), Contributions in marine mammal paleontology honoring Frank C. Whitmore, Jr. Proceedings of the San Diego Society of Natural History 29: 147-178.

FordyCE R. E. 2002. - Simocetus rayi (Odontoceti: Simocetidae) (new species, new genus, new family), a bizarre new archaic Oligocene dolphin from the eastern North Pacific. Smithsonian Contributions to Paleobiology 93: 185-222.

Fordyce R. E. \& Muizon C. DE. (2001). - Evolutionary history of cetaceans: a review, in MAZIN J.-M. \& BUfFRÉNIL V. DE (eds), Secondary Adaptation of Tetrapods to Life in Water. Verlag Dr. Friedrich Pfeil, München: 169-233.

FordyCE R. E., QUILTY P. G. \& DANIELS J. 2002. - Australodelphis mirus, a bizarre new toothless ziphiid-like fossil dolphin (Cetacea: Delphinidae) from the Pliocene of Vestfold Hills, East Antarctica. Antarctic Science 14 (1): 37-54.

Fraser F. C. \& Purves P. E. 1960. - Hearing in cetaceans: Evolution of the accessory air sacs and the structure of the outer and middle ear in recent cetaceans. Bulletin of the British Museum (Natural History), Zoology 7: 1-140.

Gatesy J., Geisler J. H., Chang J., Buell C., Berta A., Meredith R. W., Springer M. S. \& MCGowen M. R. 2013. - A phylogenetic blueprint for a modern whale. Molecular phylogenetics and evolution 66 (2): 479-506.

GeIsLER J. H. \& SANDERS A. E. 2003. - Morphological evidence for the phylogeny of Cetacea. Journal of Mammalian Evolution 10 (1-2): 23-129.

Geisler J. H., McGowen M. R., Yang G. \& Gatesy J. 2011. - A supermatrix analysis of genomic, morphological, and paleontological data for crown Cetacea. BMC Evolutionary Biology 11: 1-22.

Geisler J. H., Godfrey S. J. \& Lambert O. 2012. — A new genus and species of late Miocene inioid (Cetacea: Odontoceti) from the Meherrin River, North Carolina, U.S.A. Journal of Vertebrate Paleontology 32 (1): 198-211.

GoDFreY S. J. 2013. - On the olfactory apparatus in the Miocene odontocete Squalodon sp. (Squalodontidae). Comptes Rendus Palevol 12: 519-530

Godfrey S. J., Geisler J. H. \& Fitzgerald E. M. G. 2013. - On the olfactory anatomy in an archaic whale (Protocetidae, Cetacea) and the Minke whale Balaenoptera acutorostrata (Balaenopteridae, Cetacea). The Anatomical Record 296: 257-272.

Goloboff P. A. 1993. - Estimating character weights during tree search. Cladistics 9 (1): 83-91.

Hamilton H., Caballero S., Collins A. G. \& Brownell R. L. JR. 2001. - Evolution of river dolphins. Proceedings of the Royal Society of London (B) 268: 549-556. 
HocH E. 2000. - Olfaction in whales: evidence from a young odontocete of the Late Oligocene North Sea. Historical Biology 14 (1-2): 67-89.

KeLLOGG R. 1924. - A fossil porpoise from the Calvert Formation of Maryland. Proceedings of the United States National Museum $63(14): 1-39$.

KeLlogG R. 1932. - A Miocene long-beaked porpoise from California. Smithsonian Miscellaneous Collections 87 (2): 1-11.

LAMBert O. 2004. - Systematic revision of the Miocene longsnouted dolphin Eurhinodelphis longirostris du Bus, 1872 (Cetacea, Odontoceti, Eurhinodelphinidae). Bulletin de l'Institut royal des Sciences naturelles de Belgique, Sciences de la Terre 74: 147-174.

LAMBert O. 2005a. - Phylogenetic affinities of the long-snouted dolphin Eurhinodelphis (Cetacea, Odontoceti) from the Miocene of Antwerp. Palaeontology 48 (3): 653-679.

LAMBERT O. 2005b. - Review of the Miocene long-snouted dolphin Priscodelphinus cristatus du Bus, 1872 (Cetacea, Odontoceti) and phylogeny among eurhinodelphinids. Bulletin de l'Institut royal des Sciences naturelles de Belgique, Sciences de la Terre 75: 211-235.

LAMBERT O. 2005c. - Systematics and phylogeny of the fossil beaked whales Ziphirostrum du Bus, 1868 and Choneziphius Duvernoy, 1851 (Cetacea, Odontoceti), from the Neogene of Antwerp (North of Belgium). Geodiversitas 27 (3): 443-497.

Lambert O., Muizon C. DE \& BianucCi G. 2013. - The most basal beaked whale Ninoziphius platyrostris Muizon, 1983: clues on the evolutionary history of the family Ziphiidae (Cetacea: Odontoceti). Zoological Journal of the Linnean Society 167: 569-598.

Lambert O., BianuCCI G. \& URBina M. 2014. - Huaridelphis raimondii, a new early Miocene Squalodelphinidae (Cetacea, Odontoceti) from the Chilcatay Formation, Peru. Journal of Vertebrate Paleontology 34 (5): 987-1004.

LYDEKKER R. 1893. - Contribution to the knowledge of the fossil vertebrates of Argentina. Part II. Cetacean skulls from Patagonia. Anales del Museo de La Plata, 1893: 1-14.

Macé M., Lignereux Y., ANTOINe P.-O. \& Muizon C. DE 1999. — A new Eurhinodelphid from peruvian Miocene. Proceedings of the 13th Annual Conference of the European Cetacean Society, Valencia, 4 p.

Maddison W. P., Donoghue M. J. \& Maddison D. R. 1984. Outgroup analysis and parsimony. Systematic Biology 33 (1): 83-103.

MCGOWEN M. R., SPAUlding M. \& GATESY J. 2009. — Divergence date estimation and a comprehensive molecular tree of extant cetaceans. Molecular Phylogenetics and Evolution 53 (3): 891-906.

Mcleod C. D., Reidenberg J. S., Weller M., Santos M. B., Herman J., Goold J. \& Pierce G. J. 2007. — Breaking symmetry: The marine environment, prey size, and the evolution of asymmetry in cetacean skulls. The Anatomical Record 290:539-545.

MCHEDLIDZE G. A. 1976. - General Features of the Palaeobiological Evolution of Cetacea. [Osnovnye Cherty Paleobiologicheskoi Istorii Kitoobraznykh]. Metsniereba Publishers, Tbilisi, New Delhi, 139 p. (translated from Russian in 1984 by Amerind Publishing Co. Pvt. Ltd.).

MEAD J. G. 2007. - Stomach anatomy and use in defining systemic relationships of the cetacean family Ziphiidae (beaked whales). The Anatomical Record 290 (6): 581-595.
MEAD J. G. \& FordyCE R. E. 2009. — The therian skull: a lexicon with emphasis on the odontocetes. Smithsonian Contributions to Zoology 627: 1-248.

Muizon C. DE 1984. — Les Vertébrés de la Formation Pisco (Pérou). Deuxième partie: Les Odontocètes (Cetacea, Mammalia) du Pliocène inférieur du Sud-Sacaco. Travaux de l'Institut français d'Études andines 27: 1-188.

MuizOn C. DE 1987. - The affinities of Notocetus vanbenedeni, an Early Miocene platanistoid (Cetacea Mammalia) from Patagonia, southern Argentina. American Museum Novitates 2904: 1-27.

Muizon C. DE 1988a. — Les relations phylogénétiques des Delphinida. Annales de Paléontologie 74: 159-227.

MuizOn C. DE 1988b. — Le polyphylétisme des Acrodelphidae, odontocètes longirostres du Miocène européen. Bulletin $d u$ Muséum national d'Histoire naturelle, Paris 10: 31-88.

Muizon C. DE 1991. - A new Ziphiidae (Cetacea) from the Early Miocene of Washington State (USA) and phylogenetic analysis of the major groups of odontocetes. Bulletin du Muséum national d'Histoire naturelle, Paris 12: 279-326.

PERRIN W. F. 1975. - Variation of spotted and spinner porpoise (genus Stenella) in the eastern Pacific and Hawaii. Bulletin of the Scripps Institution of Oceanography University of California, San Diego La Jolla, California 21: 1-206.

ReidenBERG J. S. \& LAITMAN J. T. 1994. - Anatomy of the hyoid apparatus in Odontoceti (toothed whales): specializations of their skeleton and musculature compared with those of terrestrial mammals. The Anatomical Record 240: 598-624.

Schulte H. VON W. \& SMith M. DE F. 1918. - The external characters, skeletal muscles, and peripheral nerves of Kogia breviceps (Blainville). Bulletin of the American Museum of Natural History 38: 7-72.

SEAGARS D. J. 1982. - Jaw structure and functional mechanics of six delphinids (Cetacea: Odontoceti). Master's thesis, San Diego State University, San Diego, 179 p.

Steeman M. E., Hebsgaard M. B., Fordyce R. E., Ho S. Y. W., Rabosky D. L., Nielsen R., RahbeK C., GlenNer H., Sørensen M. V. \& Willerslev E. 2009. - Radiation of extant cetaceans driven by restructuring of the oceans. Systematic Biology 58 (6): 573-585.

SWOFFORD D. L. 2001. - PAUP*. Phylogenetic analysis using parsimony ( ${ }^{*}$ and other methods). Version 4610. Sinauer Associates, Sunderland, Massachusetts.

UHEN M. D. 2004. - Form, function, and anatomy of Dorudon atrox (Mammalia, Cetacea): an archaeocete from the middle to late Eocene of Egypt. University of Michigan Papers on Paleontology 34: 1-222.

Uhen M. D. 2008. - A new Xenorophus-like odontocete cetacean from the oligocene of North Carolina and a discussion of the basal odontocete radiation. Journal of Systematic Palaeontology $6(4): 433-452$.

WiLSON L. E. 1935. - Miocene marine mammals from the Bakersfield region, California. Bulletin of the Peabody Museum of Natural History 4: 1-143. 


\section{APPENDICES}

Appendix 1. - List of specimens directly examined for this work.

Albertocetus meffordorum

'Argyrocetus' bakersfieldensis

Argyrocetus patagonicus

Delphinus delphis

Berardius spp.

Chilcacetus cavirhinus n. gen., n. sp.

Eoplatanista gresalensis

Eoplatanista italica

Eosqualodon langewieschei

Eurhinodelphis cocheteuxi

E. longirostris

Huaridelphis raimondii

Hyperoodon spp.

Indopacetus pacificus

Kentriodon pernix

Macrodelphinus kelloggi

Mesoplodon spp.

Messapicetus gregarius

Nazcacetus urbinai

Ninoziphius platyrostris

Notocetus vanbenedeni

Platanista gangetica

Pomatodelphis bobengi

Pomatodelphis sp.

Schizodelphis morckhoviensis

Pontoporia blainvillei

\section{Simocetus rayi}

Squalodelphis fabianii

Squalodon bariensis

Squalodon bellunensis

Squalodon calvertensis

Squalodon whitmorei

Squaloziphius emlongi

Tasmacetus shepherdi

Xiphiacetus bossi

$X$. cristatus

Waipatia maerewhenua

Zarhinocetus errabundus

Zarhachis flagellator

Ziphiodelphis abeli

Z. sigmoideus

Ziphirostrum marginatum

$Z$. recurvus

$Z$. turniense

Ziphius cavirostris

Zygorhiza kochii
USNM 525001;

YPM 13406 (cast at IRSNB), YPM 13410, 13411 (casts at USNM);

MLP 5-7;

IRSNB 1519, 33388, 1509C, 35447; NNML 31199, MSNUP M286, 287, 289; several specimens of the two species at the MNHN, SAM, USNM, ZMA;

MNHN.F.PRU11, MUSM 1401;

MGP 26166;

MGP 26153, MGP 26409, MGP 26154;

BDNLTM 326;

IRSNB M.294, 295, 296, 297, 299, 1856, 1857;

IRSNB M.342, 1858;

MUSM 1396, 1403, 599;

numerous specimens of the two species at the IRSNB, MSNUP, SAM, RMNH, USNM, ZMA;

MZUF M4854, USNM 593534;

USNM 10670;

YPM 13402, YPM 13403;

specimens of most of the extant species at the IRSNB, MUSM, MSNUP, SAM, RMNH, USNM, ZMA;

MUSM 950, 951, 1036, 1037, 1038, 1394, 1481, 1482;

MUSM 949;

MNHN SAS 941, 1628, 1629;

MLP 5-5;

IRSNB 1507, MNHN A7943, MSNUP M272, RMNH 31169, USNM 172409, 23456;

USNM 299695;

USNM 187414;

IRSNB M.343, 345, USNM 21291, 167676, 187306;

MSNUP M273; USNM 482771, USNM 482722, USNM 482712; USNM 482724;

USNM 256517;

MGP 26134, 26141, 26378;

MGP 26081, MNHL Dr15;

GP 17715, 26091, 26131, 26322;

USNM 10484, 328343;

USNM 183023;

USNM 181528;

SAM ZM 41116, USNM 484878;

IRSNB M.367, USNM 8842, 10464, 10711, 10714, 16581;

IRSNB M.361, 1893, 1894, 1895, 1896, USNM 13436, 21303, 21360, 21363; cast MNHN;

LACM 149588, 21258;

USNM 10911, 10485;

MGP 26187;

MGP 26395;

IRSNB M.536, 537, 1874-1879;

IRSNB M.544;

IRSNB M.539, 1880;

numerous specimens at the IRSNB, MSNUP, SAM, RMNH, USNM, ZMA;

USNM 4679, 11962. 
1. Rostrum elongation (Bianucci et al. 2010, modified): short, ratio between rostrum length and condylobasal length $<0.70$ (0); elongated, ratio > $0.70(1)$.

2. Apex of the rostrum constituted only by the premaxillae on more than 10 per cent of its total length (Lambert 2005a, modified): absent (0); present with alveoli (1); present without alveoli (2).

3. Lateral rostral suture between premaxilla and maxilla deeply grooved (Fordyce, 1994): no (0); yes (1).

4. Mesorostral groove (Bianucci et al. 2007, modified): empty (0); filled by the mesorostral ossification of the vomer, without median suture between the lateral walls of the vomer in the rostrum base area (1); filled by the mesorostral ossification of the vomer, with median suture between the lateral walls of the vomer in the rostrum base area (2).

5. Medial fusion of the premaxillae on the rostrum: absent (0); present (1).

6. Deep medial depression at rostrum base: absent (0); present with ventromedially inclined dorsal surface of premaxillae (1); present with strong reduction of the premaxilla (prenarial basin sensu strico) (2).

7. Marked asymmetry of the premaxillae on the rostrum, at some distance anterior to the premaxillary foramina, with the right premaxilla distinctly narrower than the left in dorsal view (Lambert et al. 2014): absent (0); present (1).

8. Widening of the premaxillae at the rostrum base (Lambert et al. 2014): narrow premaxillae, ratio between the width of the rostrum and the transverse width of the premaxillae at the antorbital notch $<0.60(0)$; wide premaxillae, ratio between 0.60 and $0.75(1)$.

9. Dorsal opening of the mesorostral groove anterior to the rostrum base (Geisler \& Sanders 2003, modified): narrower than the premaxilla (0); wider than the premaxilla (1).

10. Deep, V-shaped, left antorbital notch, related to an anteriorly pointed antorbital process (Lambert et al. 2014): absent (0); present (1).

11. Level of the premaxillary foramen (Lambert et al. 2013): distinctly anterior to the antorbital notch (0); roughly at the level of the antorbital notch (1); distinctly posterior to the antorbital notch (2).

12. Elevated antorbital region, distinctly higher than the dorsal margin of the rostrum base in lateral view (Lambert et al. 2014): absent (0); present (1).

13. Distinct dorsal crest in the antorbital-supraorbital region (Lambert et al. 2014): absent (0); present (1).
14. Thickening of the antorbital process of the frontal (Lambert et al. 2014); absent, ratio between the height of the antorbital process of the frontal, measured in lateral view perpendicular to the maxillary-frontal suture above the orbit, and the vertical distance from the lower margin of the occipital condyles to the vertex of the skull $<0.25(0)$; present, ratio $>0.30(1)$.

15. Widening of the cranium (Lambert et al. 2014): cranium roughly as long as wide or longer than wide with ratio between cranium length (longitudinal, from occipital condyles to level of antorbital notches) and postorbital width $>0.90(0)$; cranium distinctly shorter than wide with ratio $<0.90$ (1).

16. Posterior infraorbital foramen(ina) along the vertex more medial than the lateral-most margin of the premaxilla in the cranium (Lambert et al. 2014): absent (0); present (1).

17. Deep fossa in the frontal on orbit roof, at the level of the frontal groove (Lambert et al. 2014): absent (0); present (1).

18. Asymmetry of the premaxillary sac fossae (Lambert 2005c, modified): absent or weak, ratio between the widths of the left and right premaxillary fossae $>0.65(0)$; moderate to high, ratio $\leq 0.65(1)$.

19. Ascending process of the premaxilla in lateral view (Bianucci et al. 2007): rectilinear (0); slightly concave (1); concave with posterodorsal portion vertical (2); concave with posterodorsal portion partly overhanging the bony nares (3).

20. Constriction on the ascending process of the right premaxilla (between premaxillary sac fossa and premaxillary crest) (Bianucci et al. 2007): roughly absent, ratio between the minimal width of ascending process of premaxilla and the width of right premaxillary crest $>0.80(0)$; moderate constriction, ratio between 0.80 and $0.61(1)$; strong constriction, ratio $<0.61$ (2).

21. Vertex elevation (Bianucci et al. 2007, modified): absent to weak, ratio between the vertical distance between the dorsal margin of the rostrum and the top of the vertex and the width of the premaxillary sac fossae $<0.70(0)$; moderate, ratio between 0.70 and 1.0 (1); strong, ratio > 1.0 (2).

22. Vertex distinctly shifted to the left compared to the sagittal plane of the skull (Lambert et al. 2014): absent (0); present (1).

23. Transverse premaxillary crest on the vertex (Lambert 2005c): absent (0), present (1).

24. Premaxillary crest direction (taken on the anterior edge in dorsal view) (Bianucci et al. 2007, modified): crest transversely directed (0); crest anterolaterally directed (1); crest posterolaterally directed (2); left crest anterolaterally directed and right crest posterolaterally directed (3). Cannot be scored for taxa lacking the premaxillary crests.

25. Width of the premaxillary crests (Bianucci et al. 2010): small, ratio between the width of premaxillary crests (from the 
lateral-most point of the right crest to the lateralmost point of the left crest) and the width of premaxillary sac fossae $<1.0$ (0); moderate, ratio from 1.0 to 1.25 (1); large, ratio $>1.25$ (2). Cannot be scored for taxa lacking the premaxillary crests.

26. Distance between premaxillary crests (Bianucci et al. 2007): large, ratio between the minimum distance between the right and left premaxillary crests and the width of the premaxillary sac fossae $>0.25(0)$; reduced, ratio $\leq 0.25$ (1). Cannot be scored for taxa lacking the premaxillary crests.

27. Nasal elongation (Bianucci et al. 2010, modified): very elongated nasals, ratio between the length of medial suture of nasals and the maximum width of nasals $>1.1$; elongated, ratio between 1.1 and 0.4 (1); short, ratio < 0.4 (2).

28. Anteromedial excavation of the dorsal surface of the nasal (Bianucci et al. 2007): no (0); slight anteromedial concavity (1); well-defined anteromedial depression (2); deep excavation (3).

29. Anterior margin of nasals: ratio between the distance of the occipital condyles and the anterior tip of the nasals in lateral view and the length of the neurocranium $>1.00(0)$ : ratio between 1.00 and 0.65 (1); ratio between 0.64 and 0.55 (2); ratio $<0.55$ (3)

30. Dorsal surface of the nasal rising anterodorsally: absent (0); present (1).

31. Acute anterior margin of the nasal partly overhanging the bony nares: absent (0); present (1).

32. Inclusion of the nasal in the premaxillary crest (Bianucci et al. 2007): no (0); for a short distance along the posteromedial angle of the premaxillary crest (1); until about halfway along the medial margin of the crest (2); reaching the anteromedial margin of the crest (3). Cannot be scored for taxa lacking the premaxillary crests.

33. Contact between nasal and premaxillary crest (Bianucci et al. 2007, modified): reduced, on the posterior half of the nasal (0); on more than half the length of the nasal but not the whole length (1); along the whole length of the nasal (2). Cannot be scored for taxa lacking the premaxillary crests.

34. Transverse widening of the supraoccipital: ratio between the maximum width of the supraoccipital at the lateral corners of the nuchal crest and the postorbital width $<0.60(0)$; between 0.60 and $0.70(1) ;>0.70(2)$.

35. Ventral exposure of the palatine (Muizon 1987, modified): palatine widely exposed anterior to the pterygoid (0); palatine only exposed laterally to the lateral lamina of the pterygoid (1); palatine completely covered by the pterygoid (2).

36. Lateral lamina on palatine (Muizon 1988b): absent (0); present (1).
37. Hamular fossa of the pterygoid sinus (Lambert et al. 2013): small, not reaching anteriorly the level of the antorbital notch (0); wide, extending anteriorly on the palatal surface of the rostrum (1).

38. Apices of the right and left hamular processes of the pterygoids (Lambert et al. 2013): contact medially, forming together a medial point posteriorly directed (0); diverge posterolaterally, forming together a concave $\mathrm{V}$-shaped posterior margin (1); as for the state 1 but with less excavated and U-shaped posterior margin (2).

39. Excavation of the apex of the hamular process by the fossa for the hamular lobe of the pterygoid sinus (Lambert et al. 2013): absent (0); present (1).

40. Thickening of the zygomatic process of the squamosal (Lambert et al. 2014); absent, ratio between the maximum distance from the anteroventral margin of the zygomatic process to the posterodorsal margin, in lateral view, and the vertical distance from the lower margin of the occipital condyles to the vertex of the skull $<0.35(0)$; present, ratio $>0.35$ (1).

41. Circle-shaped zygomatic process of the squamosal in lateral view (Lambert et al. 2014): absent (0); present (1).

42. Anteroposterior shortening of the zygomatic process of the squamosal (Lambert et al. 2013): absent, elongated zygomatic process, ratio between the height of the process (from the anterior tip of the process to the external auditory meatus) and the length of the process (from the dorsal margin of the zygomatic process to the ventral margin of the postglenoid process) $<1.10$ (0); short, ratio $\geq 1.10$ (1).

43. Ventral margin of the postglenoid process of the squamosal in lateral view (Lambert et al. 2013): approximately at the same level as the ventral margin of the paroccipital process (0); clearly more ventral than the ventral margin of the paroccipital process of the exoccipital (1); clearly more dorsal than the ventral margin of the paroccipital process (2).

44. Angle formed by the basioccipital crests in ventral view (Geisler \& Sanders 2003, modified): $<50^{\circ}(0) ; \geq 50^{\circ}$ (1).

45. Anteroposterior length of temporal fossa: ratio between horizontal length of the temporal fossa and the length of the neuocranium $>0.75(0)$; ratio between 0.75 to $0.44(1)$; ratio $<0.44(2)$.

46. Height of the dorsal margin of the temporal fossa in lateral view: ratio between the vertical distance from the dorsal margin of the temporal fossa to the top of the nuchal crest and the vertical distance from the ventral margin of the temporal fossa to the top of the nuchal crest $<0.10(0)$; ratio between 0.10 to 0.20 (1); between 0.20 to 0.50 (2); ratio > 0.50 (3).

47. Articular rim on the lateral surface of the periotic (Muizon 1987, modified): absent (0); present (1); present and hook-like (2). 
48. Pars cochlearis of the periotic square-shaped in ventral view (Muizon 1987): absent (0); present (1).

49. Aperture of the cochlear aqueduct of the periotic (Muizon 1987, modified): small (0); very small (1); large and thin-edged (2).

50. Aperture of the cochlear aqueduct of the periotic (Muizon 1987, modified): faces mediodorsally (0); faces dosally (1).

51. Fan-shaped posterior bullar facet of the periotic (Bianucci et al. 2010): absent (0); present (1).

52. Transverse thickening of the anterior process of the periotic (Fordyce 1994, modified): absent or slight thickening (0); marked thickening (1).

53. Extent of the lateral tuberosity of the periotic in ventral view (Lambert et al. 2013): transversely short (0); laterally elongated (1).

54. Anterior bullar facet of the periotic (Muizon 1988b): present (0); absent (1).

55. Dorsal keel on the posterior process of the periotic (Lambert et al. 2013): present on the whole length of the process (0); absent or poorly individualized (1).

56. Anterior spine of the tympanic (Muizon 1987, modified): absent, with a more or less rectilinear anterior margin $(0)$; anterior margin pointed but without a marked thickening (1); well-defined anterior spine (2); elongated anterior spine associated with a marked anterolateral convexity (3).

57. Ventral groove of the tympanic along the whole length of the bone, including the anterior spine (Muizon 1987): absent (0); present (1).

58. Extent of the inner and outer posterior prominences of the tympanic (Lambert et al. 2014): both prominences with approximately the same posterior extent (0); outer posterior prominence posteriorly longer than the inner posterior prominence (1).

59. Dorsal margin of the involucrum of the tympanic cut by a median indentation, in medial view (Lambert 2005a): absent (0), present (1).

60. Excavation of the postero-dorsal region of the involucrum of the tympanic bulla (Muizon 1988b): absent (0); present (1).

61. Anterior inflexion of the distal portion of the sigmoid process of the tympanic bulla (Muizon 1988b): absent (0); present (1).

62. Sigmoid process of the tympanic in lateral view (Lambert 2005a, modified): high, without distinct posteroventral corner (0); posteroventral corner present and posterior margin perpendicular to long axis of the tympanic (1); posteroventral corner posteriorly projected (2).

63. Shape of the facets for the incus on the malleus, in posteromedial view (Bianucci et al. 2010): elongated, ratio between the main horizontal axis length and the main vertical axis length $<1.0(0)$; approximately circular, ratio $\geq 1.0(1)$.

64. Tuberculum of the malleus (Lambert 2005a, modified): elongated tuberculum, ratio between the tuberculum and malleus lengths $>0.50(0)$; short tuberculum, ratio $\leq 0.50$ (1).

65. Apical extension of the manubrium of the malleus (Muizon 1987): absent (0); present (1).

66. Loss of double-rooted posterior teeth: (Muizon 1987): absent (0); present (1).

67. Retention of accessory denticles on posterior teeth (Muizon 1987, modified): present (0); absent (1).

68. Tooth count per upper or lower row (Lambert et al. 2014): $<25(0)$; > 25 (1). Character not scored when functional maxillary teeth are lost.

69. Functional maxillary teeth in individualized alveoli (Bianucci et al. 2010): present (0); absent (1).

70. Tusks on the mandibles (Bianucci et al. 2007, modified): absent (0); two enlarged pairs, apical to sub-apical (1); one enlarged pair, apical (2); one enlarged pair, not apical (3).

71. Length of the symphyseal portion of the mandibles (Bianucci et al. 2010, modified): elongated, ratio between length of the symphyseal portion and total length: $\geq 0.35(0)$; short, ratio $<0.35(1)$.

72. Degree of fusion of the symphysis on the mandibles (Lambert et al. 2013): reduced to absent (0); strong, dentaries nearly completely fused (1).

73. Shape of the section of the symphyseal portion of the mandibles (Muizon 1991, modified): triangular, pinched in posteroventral region (0); half-circled (1).

74. Precoronoid crest (Fordyce et al. 2002): absent, dorsal margin of the mandible rectilinear or slightly concave from the alveolar groove to the coronoid process (0); present, dorsal margin distinctly convex (1).

75. Strong development of the dorsal transverse process of the atlas and extreme reduction of its ventral process (Muizon 1987): no (0); yes (1).

76. Pairs of double-headed ribs (Lambert et al. 2013): 8 or more (0); less than 8 (1).

77. Great reduction of coracoid process of the scapula (Muizon 1987): absent (0); present (1). 
APPENDIX 3. - Character/taxon matrix. Data matrix of 77 characters for one outgroup (the basilosaurid Zygorhiza), Chilcacetus, and 33 other extinct and extant odontocete taxa. All characters with multiple states are treated as unordered; $\mathbf{0}$, primitive state; $\mathbf{1}, \mathbf{2}, \mathbf{3}$, derived states; $\mathbf{a}$, variable between 0 and 1 ; $\mathbf{b}$, variable between 1 and 2; c, variable between 2 and 3; n, character inapplicable; ?, missing character.

\begin{tabular}{|c|c|c|c|c|c|c|c|c|c|c|c|c|c|c|c|c|c|c|c|c|}
\hline & 1 & 2 & 3 & 4 & 5 & 6 & 7 & 8 & 9 & 10 & 11 & 12 & 13 & 14 & 15 & 16 & 17 & 18 & 19 & 20 \\
\hline Zygorhiza & 0 & 0 & 0 & 0 & 0 & 0 & 0 & 0 & 0 & 0 & 0 & 0 & 0 & 0 & 0 & 0 & 0 & 0 & 0 & 0 \\
\hline Squalodon & 1 & 0 & 0 & 0 & 0 & 1 & 0 & 0 & 0 & 0 & 0 & 0 & 0 & 0 & 0 & 0 & 0 & 0 & 0 & 0 \\
\hline Waipatia & 0 & 0 & 0 & 0 & 0 & 1 & 0 & 1 & 0 & 0 & 0 & 0 & 0 & 0 & 0 & 0 & 0 & 0 & 1 & 0 \\
\hline Chilcacetus n. gen. & 1 & 0 & 0 & 0 & 0 & 0 & 0 & 1 & 0 & 0 & 1 & 0 & 0 & 0 & 0 & 0 & 0 & 0 & 1 & 0 \\
\hline "Argyrocetus" bakersfieldensis & $?$ & $?$ & ? & 0 & 0 & 0 & 0 & 1 & 0 & 0 & 1 & 0 & 0 & 0 & $?$ & 0 & 0 & 0 & 1 & 0 \\
\hline "Argyrocetus" joaquinensis & $?$ & $?$ & $?$ & 0 & 0 & 0 & 0 & 0 & 1 & 0 & 1 & 0 & 0 & 0 & 0 & 0 & 0 & 0 & 1 & 0 \\
\hline Macrodelphinus & 1 & 1 & 0 & 0 & 0 & 0 & 0 & 0 & 0 & 0 & 2 & 0 & 0 & 0 & $?$ & 0 & 0 & 0 & 1 & 0 \\
\hline Argyrocetus patagonicus & 1 & $?$ & 0 & 0 & 0 & 0 & 0 & 0 & 1 & 0 & 2 & 0 & ? & $?$ & 0 & 0 & ? & 0 & 1 & 0 \\
\hline Eoplatanista & 1 & 0 & 1 & 0 & 0 & 0 & 0 & 1 & 0 & 0 & 0 & 1 & 0 & 0 & 0 & 0 & 0 & 0 & 1 & 0 \\
\hline Eurhinodelphis & 1 & 2 & 1 & 0 & 0 & 0 & 0 & 1 & 0 & 0 & 1 & 0 & 0 & 0 & 1 & 0 & 0 & 0 & 1 & 0 \\
\hline Schizodelphis & 1 & 2 & 1 & 0 & 0 & 0 & 0 & 1 & 0 & 0 & 1 & 1 & 0 & 0 & 1 & 0 & 0 & 0 & 1 & 0 \\
\hline Ziphiodelphis & 1 & 2 & 1 & 0 & 0 & 0 & 0 & 1 & 0 & 0 & 1 & 1 & 0 & 0 & 1 & 0 & 0 & 0 & 1 & 0 \\
\hline Xiphiacetus & 1 & 2 & 1 & 0 & 0 & 0 & 0 & 1 & 0 & 0 & $\mathrm{~b}$ & 1 & $\mathrm{a}$ & 0 & 1 & 0 & 0 & 0 & 1 & 0 \\
\hline Squaloziphius & $?$ & $?$ & ? & 0 & ? & 0 & 0 & 0 & 0 & 0 & 2 & 0 & 0 & 0 & 1 & 0 & 0 & 0 & 0 & 0 \\
\hline Indopacetus & 0 & 2 & 0 & $?$ & 0 & 0 & 0 & 0 & 0 & 0 & a & 0 & 0 & 0 & 1 & 0 & 0 & 0 & 2 & 2 \\
\hline Mesoplodon & 0 & 2 & 0 & 2 & 0 & 0 & 0 & 0 & 0 & 0 & 1 & 0 & 0 & 0 & 1 & 0 & 0 & 0 & 3 & 2 \\
\hline Hyperoodon & 0 & 2 & 0 & 2 & 0 & 0 & 0 & 0 & 0 & 0 & 2 & 0 & 0 & 0 & 1 & 0 & 0 & 1 & 3 & 2 \\
\hline Ziphius & 0 & 2 & 0 & 1 & 0 & 0 & 0 & 0 & 0 & 0 & 1 & 0 & 0 & 0 & 1 & 0 & 0 & 1 & 3 & 0 \\
\hline Berardius & 0 & 2 & 0 & 0 & 0 & 0 & 0 & 0 & 0 & 0 & 1 & 0 & 0 & 0 & 1 & 0 & 0 & 0 & 1 & 0 \\
\hline Nazcacetus & 0 & 0 & 0 & 0 & 0 & 0 & 0 & 0 & 0 & 0 & 1 & 0 & 0 & 0 & 1 & 0 & 0 & 0 & 2 & 1 \\
\hline Tasmacetus & 0 & 2 & 0 & 0 & 0 & 0 & 0 & 0 & 0 & 0 & 1 & 0 & 0 & 0 & 1 & 0 & 0 & 0 & 2 & 2 \\
\hline Messapicetus & 1 & 2 & 0 & 0 & 1 & 2 & 0 & 0 & 0 & 0 & 0 & 0 & 0 & 0 & 1 & 0 & 0 & 0 & 2 & 2 \\
\hline Ziphirostrum & 0 & 2 & 0 & 0 & 1 & 2 & 0 & 0 & 0 & 0 & 0 & 0 & 0 & 0 & 1 & 0 & 0 & 0 & 2 & 1 \\
\hline Ninoziphius & 1 & $?$ & 0 & 0 & 0 & 0 & 0 & 0 & 0 & 0 & 0 & 0 & 0 & 0 & 1 & 0 & 0 & 0 & 1 & $?$ \\
\hline Huaridelphis & 0 & 0 & 0 & 0 & 0 & 1 & 1 & 1 & 0 & 1 & 0 & 1 & 0 & 0 & 1 & 1 & 1 & 0 & 1 & 0 \\
\hline Notocetus & 0 & 0 & 0 & 0 & 0 & 1 & 1 & 1 & 0 & 1 & 0 & 1 & 0 & 0 & 1 & 1 & 1 & 0 & 1 & 0 \\
\hline Squalodelphis & 0 & 0 & 0 & 0 & 0 & 1 & 1 & 1 & 1 & 1 & 0 & 1 & 0 & 0 & 1 & $?$ & 1 & 0 & 1 & 0 \\
\hline Platanista & 0 & 0 & 1 & 0 & 0 & 1 & 1 & 1 & 0 & 0 & 1 & 1 & 1 & 0 & 1 & 1 & 1 & 0 & 1 & 0 \\
\hline Zarachis & 1 & 0 & 1 & 0 & 0 & 1 & 1 & 1 & 0 & 0 & 0 & 1 & 1 & 1 & 1 & 1 & 1 & 0 & 1 & 0 \\
\hline Pomatodelphis & 1 & 0 & 1 & 0 & 0 & 1 & 1 & 1 & 0 & 0 & 0 & 1 & 1 & 1 & 1 & 1 & 1 & 0 & 1 & 0 \\
\hline Zarhinocetus & 1 & 0 & 1 & 0 & 0 & 1 & 0 & 0 & 1 & 0 & 0 & 1 & 0 & 0 & 1 & 0 & $?$ & 0 & 1 & 0 \\
\hline Allodelphis & 1 & 0 & 1 & 0 & 0 & 1 & 0 & 0 & 1 & 0 & 0 & 0 & 0 & 0 & 1 & 0 & $?$ & 0 & 1 & 0 \\
\hline Kentriodon & 0 & 0 & 0 & 0 & 0 & 0 & 0 & 0 & 0 & 0 & 1 & 0 & 0 & 0 & 0 & 0 & 0 & 0 & 1 & 0 \\
\hline Pontoporia & 0 & 0 & 1 & 0 & 0 & 0 & 0 & 0 & 0 & 0 & 2 & 1 & 1 & 0 & 0 & 0 & 0 & 0 & 0 & 0 \\
\hline Delphinus & 0 & 0 & 0 & 0 & 0 & 0 & 0 & 0 & 0 & 0 & 1 & 0 & 0 & 0 & 1 & 0 & 0 & 0 & 1 & 0 \\
\hline
\end{tabular}




\begin{tabular}{|c|c|c|c|c|c|c|c|c|c|c|c|c|c|c|c|c|c|c|c|c|}
\hline & 21 & 22 & 23 & 24 & 25 & 26 & 27 & 28 & 29 & 30 & 31 & 32 & 33 & 34 & 35 & 36 & 37 & 38 & 39 & 40 \\
\hline Zygorhiza & 0 & 0 & 0 & $\mathrm{n}$ & $\mathrm{n}$ & $\mathrm{n}$ & 0 & 0 & 0 & 0 & 0 & $\mathrm{n}$ & $\mathrm{n}$ & 0 & 0 & 0 & 0 & 0 & 0 & 0 \\
\hline Squalodon & 0 & 0 & 0 & $\mathrm{n}$ & $n$ & $n$ & 2 & 0 & C & 0 & 0 & $\mathrm{n}$ & $\mathrm{n}$ & 0 & 0 & 0 & 0 & 0 & 0 & 0 \\
\hline Waipatia & 0 & 0 & 0 & $\mathrm{n}$ & $\mathrm{n}$ & $\mathrm{n}$ & 2 & 0 & 1 & 0 & 1 & $n$ & $\mathrm{n}$ & 0 & 0 & 0 & 0 & $?$ & $?$ & 0 \\
\hline Chilcacetus n. gen. & 0 & 0 & 0 & $\mathrm{n}$ & $n$ & $\mathrm{n}$ & 2 & 0 & 1 & 1 & 1 & $\mathrm{n}$ & $\mathrm{n}$ & 1 & 0 & 0 & 0 & 0 & 0 & 0 \\
\hline "Argyrocetus" bakersfieldensis & 0 & 0 & 0 & $\mathrm{n}$ & $\mathrm{n}$ & $\mathrm{n}$ & 2 & 0 & $?$ & 1 & 1 & $\mathrm{n}$ & $\mathrm{n}$ & 1 & 0 & 0 & 0 & $?$ & ? & $?$ \\
\hline "Argyrocetus" joaquinensis & 0 & 0 & 0 & $\mathrm{n}$ & $\mathrm{n}$ & $n$ & $?$ & 0 & 2 & 1 & 0 & $\mathrm{n}$ & $n$ & $?$ & 0 & 0 & 0 & 0 & 0 & 0 \\
\hline Macrodelphinus & $?$ & $?$ & 0 & $\mathrm{n}$ & $\mathrm{n}$ & $\mathrm{n}$ & 2 & 0 & $?$ & 1 & 1 & $\mathrm{n}$ & $\mathrm{n}$ & $?$ & 0 & 0 & 0 & $?$ & ? & $?$ \\
\hline Argyrocetus patagonicus & 0 & 0 & 0 & $n$ & $n$ & $n$ & 2 & 0 & 2 & 1 & 1 & $n$ & $n$ & 1 & 0 & 0 & 0 & $?$ & ? & 0 \\
\hline Eoplatanista & 0 & 0 & 0 & $\mathrm{n}$ & $\mathrm{n}$ & $\mathrm{n}$ & 2 & 0 & 1 & a & 0 & $\mathrm{n}$ & $\mathrm{n}$ & 1 & 0 & 0 & 0 & $?$ & $?$ & 0 \\
\hline Eurhinodelphis & 0 & 0 & 1 & $n$ & $n$ & $\mathrm{n}$ & 2 & 0 & 2 & 0 & 0 & $n$ & $n$ & 2 & 0 & 0 & 0 & $?$ & $?$ & 0 \\
\hline Schizodelphis & 0 & 0 & 0 & $\mathrm{n}$ & $\mathrm{n}$ & $\mathrm{n}$ & 2 & 0 & 3 & 0 & 0 & $\mathrm{n}$ & $\mathrm{n}$ & 2 & 0 & 0 & 0 & 0 & 0 & 0 \\
\hline Ziphiodelphis & 0 & 0 & 1 & $\mathrm{n}$ & $n$ & $n$ & 2 & 0 & 2 & 1 & 0 & $n$ & $n$ & 2 & 0 & 0 & 0 & $?$ & ? & 0 \\
\hline Xiphiacetus & 0 & 0 & 0 & $\mathrm{n}$ & $\mathrm{n}$ & $\mathrm{n}$ & 2 & 0 & 3 & 0 & 0 & $\mathrm{n}$ & $\mathrm{n}$ & 2 & 0 & 0 & 0 & $?$ & $?$ & 0 \\
\hline Squaloziphius & 0 & 0 & 1 & 0 & 1 & - & 1 & 0 & 3 & 0 & 0 & $n$ & $n$ & 2 & 0 & 0 & 1 & 0 & 0 & 0 \\
\hline Indopacetus & 2 & 0 & 1 & 2 & 2 & 0 & 1 & 2 & 2 & 0 & 0 & 1 & 1 & 2 & 0 & 0 & 1 & 2 & 1 & 0 \\
\hline Mesoplodon & 2 & 0 & 1 & 2 & 1 & 1 & 1 & 3 & 1 & 0 & 0 & 1 & 2 & 2 & 0 & 0 & 1 & 2 & 1 & 0 \\
\hline Hyperoodon & 2 & 1 & 1 & 2 & 2 & 1 & 1 & 3 & 3 & 0 & 0 & 2 & 2 & 2 & 0 & 0 & 1 & 2 & 1 & 0 \\
\hline Ziphius & 2 & 1 & 1 & 1 & 0 & 0 & 0 & 0 & 2 & 0 & 0 & 0 & a & 2 & 0 & 0 & 1 & 2 & 1 & 0 \\
\hline Berardius & 1 & 0 & 1 & 0 & 1 & 0 & 1 & 0 & 3 & 0 & 0 & 0 & 1 & 2 & 0 & 0 & 1 & 2 & 1 & 0 \\
\hline Nazcacetus & 0 & 0 & 1 & 0 & 0 & 0 & 1 & 1 & 1 & 0 & 0 & 0 & 1 & 2 & 0 & 0 & 1 & $?$ & ? & 0 \\
\hline Tasmacetus & 1 & 0 & 1 & 0 & 0 & 0 & 1 & 1 & 2 & 0 & 0 & 0 & 1 & 2 & 0 & 0 & 1 & 1 & 1 & 0 \\
\hline Messapicetus & 1 & 0 & 1 & 1 & 1 & 0 & 2 & 1 & 2 & 0 & 0 & 0 & 0 & 2 & 0 & 0 & 1 & 1 & 1 & 0 \\
\hline Ziphirostrum & 2 & 0 & 1 & 1 & 1 & 0 & 1 & 1 & $?$ & 0 & 0 & 0 & 0 & 2 & 0 & 0 & 1 & $?$ & $?$ & 0 \\
\hline Ninoziphius & 2 & 0 & 1 & 1 & $?$ & 0 & 1 & 0 & 3 & 0 & 0 & 0 & 0 & 2 & 0 & 0 & 1 & 1 & 0 & 0 \\
\hline Huaridelphis & 0 & 1 & 0 & $\mathrm{n}$ & $\mathrm{n}$ & $\mathrm{n}$ & 2 & 0 & 3 & 0 & 0 & $\mathrm{n}$ & $\mathrm{n}$ & 1 & 1 & 0 & 1 & $?$ & $?$ & 1 \\
\hline Notocetus & 0 & 1 & 0 & $n$ & $n$ & $n$ & 2 & 0 & 3 & 0 & 0 & $n$ & $n$ & 0 & 1 & 0 & 1 & $?$ & $?$ & 1 \\
\hline Squalodelphis & 0 & 1 & 0 & $\mathrm{n}$ & $\mathrm{n}$ & $\mathrm{n}$ & 2 & 0 & 3 & 0 & 0 & $\mathrm{n}$ & $\mathrm{n}$ & 0 & $?$ & 0 & 1 & $?$ & ? & 1 \\
\hline Platanista & 0 & 1 & 0 & $\mathrm{n}$ & $n$ & $n$ & 2 & 0 & 3 & 0 & 0 & $n$ & $n$ & 0 & 2 & 0 & 1 & 0 & 0 & 1 \\
\hline Zarachis & 0 & 1 & 0 & $\mathrm{n}$ & $\mathrm{n}$ & $\mathrm{n}$ & 2 & 0 & 3 & 0 & 0 & $\mathrm{n}$ & $\mathrm{n}$ & 1 & 1 & 0 & 1 & $?$ & $?$ & 1 \\
\hline Pomatodelphis & 0 & 1 & 0 & $\mathrm{n}$ & $n$ & $\mathrm{n}$ & 2 & 0 & 3 & 0 & 0 & $n$ & $n$ & 2 & 1 & 0 & 1 & $?$ & $?$ & 1 \\
\hline Zarhinocetus & 0 & 1 & 0 & $\mathrm{n}$ & $\mathrm{n}$ & $\mathrm{n}$ & 2 & 0 & 3 & 0 & 0 & $\mathrm{n}$ & $\mathrm{n}$ & 2 & 0 & 0 & 1 & 0 & 0 & 0 \\
\hline Allodelphis & 0 & 1 & 0 & $n$ & $n$ & $n$ & 2 & 0 & $?$ & 0 & 0 & $n$ & $n$ & 2 & 1 & 0 & 1 & $?$ & ? & 0 \\
\hline Kentriodon & 0 & 0 & 0 & $\mathrm{n}$ & $\mathrm{n}$ & $\mathrm{n}$ & 2 & 0 & 2 & 0 & 0 & $\mathrm{n}$ & $\mathrm{n}$ & 2 & 0 & 1 & 1 & $?$ & $?$ & 0 \\
\hline Pontoporia & 0 & 0 & 0 & $n$ & $n$ & $n$ & 1 & 0 & 3 & 0 & 0 & $n$ & $n$ & 2 & 0 & 1 & 0 & 2 & 1 & 0 \\
\hline Delphinus & 1 & 1 & 0 & $\mathrm{n}$ & $\mathrm{n}$ & $\mathrm{n}$ & 2 & 0 & 3 & 0 & 0 & $\mathrm{n}$ & $\mathrm{n}$ & 2 & 0 & 1 & 1 & 2 & 1 & 0 \\
\hline
\end{tabular}




\begin{tabular}{|c|c|c|c|c|c|c|c|c|c|c|c|c|c|c|c|c|c|c|c|c|}
\hline & 41 & 42 & 43 & 44 & 45 & 46 & 47 & 48 & 49 & 50 & 51 & 52 & 53 & 54 & 55 & 56 & 57 & 58 & 59 & 60 \\
\hline Zygorhiza & 0 & 0 & 0 & 0 & 0 & 0 & 0 & 0 & 0 & 0 & 0 & 0 & 0 & 0 & 0 & 0 & 0 & 0 & 0 & 0 \\
\hline Squalodon & 0 & 0 & 0 & 0 & 1 & 0 & 0 & 0 & 0 & 0 & 0 & 0 & 0 & 0 & 0 & 2 & 0 & 0 & 0 & 0 \\
\hline Waipatia & 0 & 0 & 0 & 1 & 1 & 1 & 0 & 0 & 0 & 0 & 0 & 0 & 0 & 0 & 0 & 1 & 0 & 0 & 0 & 0 \\
\hline Chilcacetus n. gen. & 0 & 0 & 0 & 0 & 1 & 1 & 0 & 0 & 0 & 0 & 0 & 0 & 0 & 0 & $?$ & 1 & 0 & 1 & 1 & 0 \\
\hline "Argyrocetus" bakersfieldensis & $?$ & $?$ & $?$ & $?$ & $?$ & ? & $?$ & $?$ & $?$ & ? & $?$ & $?$ & $?$ & $?$ & ? & ? & $?$ & $?$ & $?$ & $?$ \\
\hline "Argyrocetus" joaquinensis & 0 & 0 & 2 & 0 & 1 & 1 & $?$ & $?$ & $?$ & $?$ & $?$ & $?$ & $?$ & 0 & $?$ & 1 & 0 & 0 & $?$ & 0 \\
\hline Macrodelphinus & $?$ & $?$ & $?$ & $?$ & $?$ & $?$ & $?$ & $?$ & $?$ & $?$ & $?$ & $?$ & $?$ & $?$ & $?$ & 1 & $?$ & $?$ & ? & $?$ \\
\hline Argyrocetus patagonicus & 0 & $?$ & 1 & 1 & $?$ & 2 & $?$ & $?$ & $?$ & $?$ & ? & $?$ & $?$ & $?$ & ? & ? & $?$ & $?$ & ? & $?$ \\
\hline Eoplatanista & 0 & 0 & 0 & 0 & 1 & 0 & 0 & 0 & 0 & 0 & 0 & 0 & 0 & 0 & 0 & 1 & 0 & 1 & 1 & 0 \\
\hline Eurhinodelphis & 0 & 1 & 0 & 0 & 2 & 2 & 0 & 0 & 0 & 0 & 0 & 0 & 0 & 0 & 0 & 1 & 0 & 1 & 1 & 0 \\
\hline Schizodelphis & 0 & 1 & 0 & 0 & 2 & 3 & 0 & 0 & 0 & 0 & 0 & 0 & 0 & 0 & 0 & 1 & 0 & 1 & 1 & 0 \\
\hline Ziphiodelphis & 0 & 1 & 0 & 0 & 1 & 2 & 0 & 0 & 0 & 0 & 0 & 0 & 0 & 0 & 0 & 1 & 0 & 1 & 1 & 0 \\
\hline Xiphiacetus & $\mathrm{a}$ & 1 & 1 & 1 & 2 & 2 & 0 & 0 & 0 & 0 & 0 & 0 & 0 & 0 & 0 & 1 & 0 & 1 & 1 & 0 \\
\hline Squaloziphius & 0 & 0 & 1 & 1 & 1 & 2 & $?$ & $?$ & ? & $?$ & $?$ & $?$ & $?$ & $?$ & $?$ & $?$ & $?$ & $?$ & $?$ & $?$ \\
\hline Indopacetus & 0 & 1 & 2 & 1 & 2 & 3 & 0 & 0 & 0 & 0 & i & 1 & 1 & 0 & 1 & 0 & 0 & 1 & 1 & 0 \\
\hline Mesoplodon & 0 & 1 & 2 & 1 & 2 & 3 & 0 & 0 & 0 & 0 & 1 & 1 & 1 & 0 & 1 & 0 & 0 & a & 1 & 0 \\
\hline Hyperoodon & 0 & 1 & 2 & 1 & 2 & 3 & 0 & 0 & 0 & 0 & 1 & 1 & 1 & 0 & 1 & 0 & 0 & 1 & 1 & 0 \\
\hline Ziphius & 0 & 1 & 2 & 1 & 2 & 3 & 0 & 0 & 0 & 0 & 1 & 1 & 1 & 0 & 1 & 0 & 0 & 1 & 1 & 0 \\
\hline Berardius & 0 & 1 & 2 & 1 & 2 & 3 & 0 & 0 & 0 & 0 & 1 & 1 & 1 & 0 & 1 & 0 & 0 & 1 & 1 & 0 \\
\hline Nazcacetus & 0 & 1 & 2 & $?$ & 2 & 3 & 0 & 0 & 0 & 0 & 1 & 1 & 1 & 0 & 1 & $?$ & $?$ & $?$ & 1 & 0 \\
\hline Tasmacetus & 0 & 1 & 2 & 1 & 1 & 2 & 0 & 0 & 0 & 0 & 1 & 1 & 1 & 0 & 1 & 0 & 0 & 0 & 1 & 0 \\
\hline Messapicetus & 0 & 1 & 2 & 0 & 1 & 2 & 0 & 0 & 0 & 0 & 0 & 0 & 0 & 0 & 1 & 2 & 0 & $a$ & 1 & 0 \\
\hline Ziphirostrum & 0 & $?$ & $?$ & $?$ & ? & $?$ & $?$ & $?$ & $?$ & ? & ? & $?$ & $?$ & ? & ? & $?$ & $?$ & $?$ & ? & $?$ \\
\hline Ninoziphius & 0 & 1 & 2 & a & 1 & 2 & 0 & 0 & 0 & 0 & 0 & 0 & 0 & 0 & 1 & 0 & 0 & 1 & 1 & 0 \\
\hline Huaridelphis & 1 & 0 & $?$ & $?$ & 1 & 2 & 1 & 1 & 2 & 1 & 0 & 0 & 0 & 0 & 0 & ? & $?$ & $?$ & $?$ & 0 \\
\hline Notocetus & 1 & 0 & 0 & 0 & 1 & 2 & 1 & 1 & 2 & 1 & 0 & 0 & 0 & 0 & 0 & 3 & 1 & 0 & 0 & 0 \\
\hline Squalodelphis & 0 & 0 & 0 & $?$ & 1 & 2 & 1 & 1 & 2 & 1 & 0 & 0 & 0 & 0 & 0 & 3 & 1 & 0 & 0 & 0 \\
\hline Platanista & 0 & 0 & 1 & 1 & 1 & 0 & 2 & 0 & 1 & 0 & 0 & 1 & 0 & 0 & 0 & 3 & 0 & 1 & 0 & 0 \\
\hline Zarachis & 0 & 0 & 0 & 0 & 1 & 2 & 2 & 0 & 0 & 0 & 0 & 0 & 0 & 0 & 0 & 3 & 0 & 1 & 0 & 0 \\
\hline Pomatodelphis & 0 & 0 & 0 & 0 & 1 & 2 & 2 & 0 & 0 & 0 & 0 & 0 & 0 & 0 & 0 & 3 & 0 & 1 & 0 & 0 \\
\hline Zarhinocetus & 0 & 1 & 0 & 0 & 1 & 2 & $?$ & 0 & 0 & 0 & 0 & 0 & 0 & 0 & 0 & ? & $?$ & $?$ & $?$ & $?$ \\
\hline Allodelphis & 0 & 1 & 0 & 0 & 1 & 2 & $?$ & $?$ & $?$ & $?$ & 0 & 0 & $?$ & ? & ? & ? & $?$ & $?$ & ? & $?$ \\
\hline Kentriodon & 0 & 0 & 2 & 1 & 1 & 2 & 0 & 0 & 0 & 0 & 0 & 0 & 0 & 0 & 1 & 0 & 0 & 0 & 0 & 1 \\
\hline Pontoporia & 0 & 0 & 2 & 0 & 1 & 2 & 0 & 0 & 0 & 0 & 0 & 0 & 0 & 1 & 1 & 0 & 0 & 1 & 0 & 1 \\
\hline Delphinus & 0 & 1 & 2 & 0 & 2 & 2 & 0 & 0 & 0 & 0 & 0 & 0 & 0 & 1 & 1 & 0 & 0 & 1 & 0 & 1 \\
\hline
\end{tabular}




\begin{tabular}{|c|c|c|c|c|c|c|c|c|c|c|c|c|c|c|c|c|c|}
\hline & 61 & 62 & 63 & 64 & 65 & 66 & 67 & 68 & 69 & 70 & 71 & 72 & 73 & 74 & 75 & 76 & 77 \\
\hline Zygorhiza & 0 & 0 & 0 & 0 & 0 & 0 & 0 & 0 & 0 & 0 & 0 & 0 & 0 & 0 & 0 & $?$ & 0 \\
\hline Squalodon & 0 & 0 & 0 & 0 & 0 & 0 & 0 & 0 & 0 & 0 & 0 & 0 & 0 & 0 & 0 & $?$ & $?$ \\
\hline Waipatia & 0 & 0 & $?$ & $?$ & 0 & 0 & 0 & 0 & 0 & 0 & 1 & 0 & 0 & 0 & 0 & $?$ & $?$ \\
\hline Chilcacetus n. gen. & 0 & 0 & $?$ & $?$ & $?$ & 1 & 1 & 1 & 0 & $?$ & 0 & 0 & 0 & 0 & $?$ & $?$ & $?$ \\
\hline "Argyrocetus" bakersfieldensis & $?$ & $?$ & $?$ & $?$ & $?$ & 1 & $?$ & $?$ & 0 & $?$ & $?$ & $?$ & $?$ & $?$ & $?$ & $?$ & $?$ \\
\hline "Argyrocetus" joaquinensis & 0 & $?$ & $?$ & $?$ & $?$ & 1 & $?$ & $?$ & 0 & $?$ & $?$ & $?$ & $?$ & $?$ & $?$ & $?$ & $?$ \\
\hline Macrodelphinus & $?$ & 0 & $?$ & $?$ & $?$ & 1 & $?$ & 1 & 0 & $?$ & 0 & 0 & 0 & $?$ & $?$ & $?$ & $?$ \\
\hline Argyrocetus patagonicus & $?$ & $?$ & $?$ & $?$ & ? & 1 & $?$ & 1 & 0 & 0 & 0 & 1 & 0 & 0 & $?$ & $?$ & $?$ \\
\hline Eoplatanista & 0 & 0 & 0 & 0 & 0 & 1 & 1 & 1 & 0 & 0 & 0 & 1 & 0 & 0 & 0 & $?$ & $?$ \\
\hline Eurhinodelphis & 0 & $?$ & 0 & 1 & 0 & 1 & $?$ & 1 & 0 & 0 & $?$ & $?$ & $?$ & $?$ & 0 & $?$ & $?$ \\
\hline Schizodelphis & 0 & 0 & 0 & 1 & $?$ & 1 & 1 & 1 & 0 & 0 & 0 & 1 & 0 & 0 & ? & $?$ & $?$ \\
\hline Ziphiodelphis & 0 & 0 & 0 & 1 & 0 & 1 & 1 & 1 & 0 & $?$ & 0 & 1 & 0 & 0 & 0 & $?$ & $?$ \\
\hline Xiphiacetus & 0 & 0 & 0 & 0 & 0 & 1 & 1 & 1 & 0 & 0 & 0 & 1 & 0 & $?$ & 0 & $?$ & 0 \\
\hline Squaloziphius & $?$ & $?$ & $?$ & $?$ & $?$ & $?$ & $?$ & $?$ & $?$ & $?$ & $?$ & $?$ & $?$ & $?$ & ? & $?$ & $?$ \\
\hline Indopacetus & 0 & $?$ & $?$ & $?$ & ? & 1 & 1 & $\mathrm{n}$ & 1 & 2 & 1 & 0 & 0 & 1 & 0 & 1 & 0 \\
\hline Mesoplodon & 0 & 2 & 1 & 1 & 0 & 1 & 1 & $n$ & 1 & 3 & 1 & 0 & 0 & 1 & 0 & 1 & 0 \\
\hline Hyperoodon & 0 & 2 & $?$ & $?$ & $?$ & 1 & 1 & $\mathrm{n}$ & 1 & 2 & 1 & 0 & 0 & 1 & 0 & 1 & 0 \\
\hline Ziphius & 0 & 2 & 1 & 1 & 0 & 1 & 1 & $n$ & 1 & 2 & 1 & 0 & 0 & 1 & 0 & 1 & 0 \\
\hline Berardius & 0 & 2 & $?$ & $?$ & $?$ & 1 & 1 & $\mathrm{n}$ & 1 & 1 & 1 & 0 & 1 & 1 & 0 & 0 & 0 \\
\hline Nazcacetus & 0 & $?$ & $?$ & $?$ & $?$ & 1 & 1 & 1 & 1 & 2 & 1 & 0 & 0 & 1 & 0 & $?$ & $?$ \\
\hline Tasmacetus & 0 & 2 & 1 & 1 & 0 & 1 & 1 & 1 & 0 & 1 & 1 & 1 & 0 & 1 & 0 & 1 & 0 \\
\hline Messapicetus & 0 & 2 & 0 & 1 & 0 & 1 & 1 & 1 & 0 & 2 & 0 & 1 & 1 & 1 & $?$ & $?$ & $?$ \\
\hline Ziphirostrum & $?$ & $?$ & $?$ & $?$ & $?$ & 1 & 1 & 1 & $a$ & $?$ & $?$ & $?$ & $?$ & $?$ & ? & $?$ & $?$ \\
\hline Ninoziphius & 0 & 1 & $?$ & $?$ & $?$ & 1 & 1 & 1 & 0 & 2 & 0 & 1 & 1 & 1 & 0 & 0 & $?$ \\
\hline Huaridelphis & 0 & $?$ & $?$ & $?$ & $?$ & 1 & 0 & 0 & 0 & 0 & 0 & 1 & 0 & 0 & 1 & $?$ & $?$ \\
\hline Notocetus & 0 & 0 & 0 & 0 & 1 & 1 & 0 & 0 & 0 & 0 & 0 & 1 & 0 & 0 & 1 & $?$ & 1 \\
\hline Squalodelphis & 0 & 0 & 0 & 0 & 1 & 1 & 0 & 1 & 0 & 0 & 0 & 1 & 0 & 0 & ? & $?$ & $?$ \\
\hline Platanista & 0 & 0 & 0 & 0 & 0 & 1 & 1 & 1 & 0 & 0 & 0 & 1 & 0 & 0 & 0 & 0 & 1 \\
\hline Zarachis & 0 & 0 & 0 & 0 & 0 & 1 & 1 & 1 & 0 & 0 & 0 & 1 & 0 & 0 & 0 & $?$ & $?$ \\
\hline Pomatodelphis & 0 & 0 & 0 & 0 & 0 & 1 & 1 & 1 & 0 & $?$ & $?$ & $?$ & $?$ & $?$ & 0 & $?$ & $?$ \\
\hline Zarhinocetus & $?$ & $?$ & $?$ & $?$ & $?$ & 1 & $?$ & 1 & 0 & $?$ & $?$ & 1 & 0 & 0 & $?$ & $?$ & $?$ \\
\hline Allodelphis & $?$ & $?$ & $?$ & $?$ & $?$ & 1 & $?$ & 1 & 0 & $?$ & 0 & 1 & 0 & 0 & $?$ & $?$ & $?$ \\
\hline Kentriodon & 1 & 1 & 0 & 1 & 0 & 1 & 1 & 1 & 0 & 0 & 1 & 1 & 0 & 0 & 0 & 1 & 0 \\
\hline Pontoporia & 1 & 1 & 0 & 1 & 0 & 1 & 1 & 1 & 0 & 0 & 0 & 1 & 0 & 0 & 0 & 1 & 0 \\
\hline Delphinus & 1 & 1 & 0 & 1 & 0 & 1 & 1 & 1 & 0 & 0 & 1 & 0 & 0 & 1 & 0 & 1 & 0 \\
\hline
\end{tabular}

